\title{
A meteo-hydrological prediction system based on a multi-model approach for precipitation forecasting
}

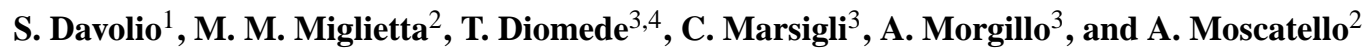 \\ ${ }^{1}$ Institute of Atmospheric Sciences and Climate, ISAC-CNR, Bologna, Italy \\ ${ }^{2}$ Institute of Atmospheric Sciences and Climate, ISAC-CNR, Lecce, Italy \\ ${ }^{3}$ Regional Hydro-Meteorological Service ARPA-SIM, Bologna, Italy \\ ${ }^{4}$ Centro Interuniversitario di Ricerca in Monitoraggio Ambientale (CIMA), Università degli studi di Genova e della \\ Basilicata, Savona, Italy
}

Received: 9 October 2007 - Revised: 25 January 2008 - Accepted: 25 January 2008 - Published: 28 February 2008

\begin{abstract}
The precipitation forecasted by a numerical weather prediction model, even at high resolution, suffers from errors which can be considerable at the scales of interest for hydrological purposes. In the present study, a fraction of the uncertainty related to meteorological prediction is taken into account by implementing a multi-model forecasting approach, aimed at providing multiple precipitation scenarios driving the same hydrological model. Therefore, the estimation of that uncertainty associated with the quantitative precipitation forecast (QPF), conveyed by the multimodel ensemble, can be exploited by the hydrological model, propagating the error into the hydrological forecast.

The proposed meteo-hydrological forecasting system is implemented and tested in a real-time configuration for several episodes of intense precipitation affecting the Reno river basin, a medium-sized basin located in northern Italy (Apennines). These episodes are associated with flood events of different intensity and are representative of different meteorological configurations responsible for severe weather affecting northern Apennines.

The simulation results show that the coupled system is promising in the prediction of discharge peaks (both in terms of amount and timing) for warning purposes. The ensemble hydrological forecasts provide a range of possible flood scenarios that proved to be useful for the support of civil protection authorities in their decision.
\end{abstract}

Correspondence to: S. Davolio

(s.davolio@isac.cnr.it)

\section{Introduction}

Severe weather events and heavy precipitations occurring over complex terrain are often associated with flood, producing risk conditions for society and environment. Accurate and reliable meteo-hydrological forecasts, issued with sufficient lead time, may result in the reduction of flood damages and efficient management of the risk. For these reasons, the scientific community has increasingly devoted resources and attention to bring together hydrological and meteorological communities and, in particular, to couple meteorological and hydrological models in order to provide more accurate and timely flood forecasts.

During the last few years, several international research projects have dealt with different aspects of this subject. For example, RAPHAEL (Runoff and Atmospheric Processes for flood HAzard forEcasting and controL) project (Bacchi and Ranzi, 2000) was aimed at developing and implementing coupled meteo-hydrological systems at the regional scale to improve flood forecasting and management in mountain catchments. More recently, HEPEX (Hydrological Ensemble Prediction EXperiment) has been focusing on the ensemble prediction approach, with the aim of meeting end-users' needs, in order to implement decision making procedures (Hamill et al., 2005; Schaake at al., 2007). The European COST Action 731, "Propagation of Uncertainty in Advanced Meteo-Hydrological Forecast Systems" addresses the problem of forecasting (heavy) precipitation events and the corresponding hydrological processes and to thoroughly investigate the propagation of uncertainty through the various steps of modelling and decision making (Rossa et al., 2005). Finally, a more operational approach is proposed by MAP D-PHASE (Mesoscale Alpine Programme, Demonstration of Probabilistic Hydrological and Atmospheric Simulation of flood Events in the Alps) project,

Published by Copernicus Publications on behalf of the European Geosciences Union. 
an end-to-end forecasting system for Alpine flood events that has been set up to demonstrate state-of-the-art forecasting of precipitation-related high-impact weather (Rotach et al., 2005).

The need for coupled meteorological and hydrological models can be understood considering that quantitative information about rainfall is an essential input for hydrological forecasts. For very large catchments, hydrological prediction can be based upon rainfall observations, since the response time of the basin is long enough to allow for timely civil protection plans. On the contrary, for medium sized (from 1000 to $10000 \mathrm{~km}^{2}$ ) and smaller catchments characterized by complex orography, the response times are usually shorter, of the order of a few hours. Therefore, hydrological models need an alternative forcing function (Melone et al., 2005 ) so that timely river flow forecasts, with lead time from several days (early warning) to $24-48 \mathrm{~h}$ (warning and alarms) ahead, can be provided by coupling hydrological models and meteorological numerical weather prediction (NWP) models.

Precise and suitable discharge predictions require accurate precipitation forecasts in terms of both spatial and temporal details: in other terms, the quality of meteorological forecasts can be a key controlling factor for the quality of a hydrological forecast (Pappenberger et al., 2005). This is particularly relevant in mountainous regions, where intense rainfalls quite often produce a rapid rise in water level and sudden flow peak. Unfortunately, precipitation forecasting is probably the most difficult task for NWP models, since rain is the end result of many complex and interacting processes ranging from the large scale motions to the microphysics. Moreover, further complexity arises over mountainous areas, since the orographic forcing needs to be properly resolved and described (Richard et al., 2007). Although the use of high resolution limited-area models (LAMs) has improved the short-range prediction of locally intense events, it is sometimes difficult to forecast accurately their space-time evolution, especially for ranges longer than $48 \mathrm{~h}$ (Marsigli et al., 2005), so that quantitative precipitation forecasts (QPF) is still a challenging task at the scale of interest for hydrological prediction.

The extent to which a QPF is beneficial for hydrological predictions depends considerably on the ability of the NWP models to resolve the scales and processes relevant for hydrological applications (Gebhardt et al., 2007). Nowadays, due to the rapid progress in computing performance and atmospheric modelling, high-resolution NWP models run with horizontal grid resolution down to a few kilometres and are used to predict weather operationally at local scales, filling the gap in the spatial scale with the hydrological models. The very small grid spacing employed allows to explicitly (without parameterization) simulate small-scale processes which are relevant also for hydrology, such as deep convection which is often involved in severe weather episodes. Moreover, higher resolution means a much better representation of the orography and improved description of fine-scale effects in mountainous areas, such as lifting or blocking. Of course, even at such high resolutions, models are not perfect and can not describe the atmospheric motion and predict the precipitation field exactly.

Although the main uncertainty of a flood forecasting system results from the rainfall prediction (Krzysztofowicz, 1999; Koussis et al., 2003; Ebert et al., 2006; Ranzi et al., 2007), the uncertainties associated with the hydrological models should be considered too. Each model component has its own source of uncertainty, producing a sort of cascade of errors propagating from the atmospheric conditions to rainfall forecasts, from rainfall to runoff prediction, and from runoff to flood wave (Pappenberger et al., 2005).

To cope and deal with all these uncertainties, forecasts have to be provided in a probabilistic form, following an ensemble approach (Hou et al., 2007). This procedure allows to provide both the most likely evolution, represented by the ensemble mean, and an estimate of the range of the possible outcomes (ensemble spread), that should be taken into account in the decision making process. Although still associated with uncertainties, progressively increasing for longer lead times, this information is beneficial for the hydrological services because it provides likely flood scenarios and the possibility for a flood event in the near future (Thielen at al., 2007). As a consequence, users of hydrological forecasts prefer more and more quantitative estimates of forecast uncertainty rather than the single most likely scenario.

Probabilistic approaches to quantify uncertainties of flood predictions have been applied recently (Siccardi et al., 2005) and ensemble predictions have been increasingly exploited in flood forecasting systems (de Roo et al., 2003; Gouweleeuw et al., 2005; Pappenberger et al., 2005; Diomede at al., 2008): the operational use of ensemble prediction systems for probabilistic flood forecasting, based on NWP models providing an input to hydrological models, represents a challenge for the scientific community and for decision makers (Krzysztofowicz, 2001; Montani et al., 2003; Moore et al., 2006; Ramos et al., 2007).

Recent efforts to generate short-range hydrological ensemble forecasts on the Reno river basin (Fig. 1) have been done by coupling an atmospheric multi-model ensemble, based on different high resolution limited area models, with an hydrological model (Diomede et al., 2008). This approach allows to represent the uncertainty intrinsic in the meteorological models (which is only a fraction of the total uncertainty in the forecasting process) exploiting the fact that models from different institutes have been developed almost independently and, thus, numerical and physical schemes are different among them. The results, based on a few case studies, were promising.

The aim of the present study is to deepen and consolidate the findings of Diomede et al. (2008) by extending the previous results to a wider range of weather events, representative of different meteorological configurations typically 


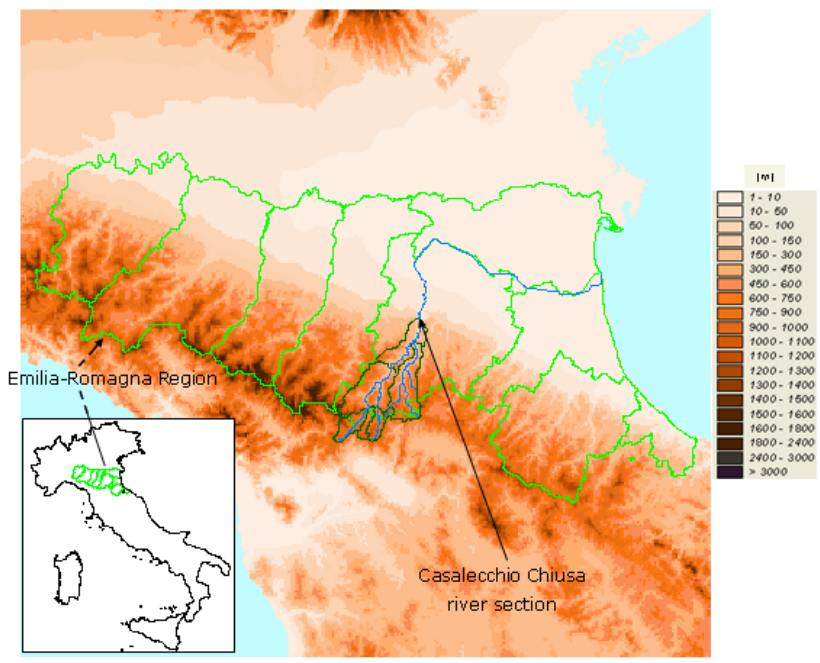

Fig. 1. Localisation of the Reno river basin, its sub-catchments (light green line) and the main river (cyan). The upper basin closed at Casalecchio Chiusa river section is evidenced with dark green lines.

affecting northern Apennines and responsible for remarkable river flow increasing. The multi-model approach produces a range of possible meteorological inputs to feed the same hydrological model. In this way, the uncertainty associated with the meteorological forecasts can propagate into the hydrological model, providing an estimation of the uncertainty associated with the discharge prediction. The performance of the probabilistic coupled system, implemented in a realtime configuration, is evaluated for the Reno river basin, a medium-sized catchment (total dimension about $5000 \mathrm{~km}^{2}$ ) located in northern Italy (Fig. 1).

Meteorological and hydrological models are briefly described in Sect. 2. Section 3 is devoted to the description and analyses of the three case studies. A general discussion is presented in Sect. 4 and concluding remarks are drawn in Sect. 5.

\section{Meteorological and hydrological models set up}

The hydrological predictions are performed using TOPKAPI (TOPographic Kinematic APproximation and Integration) (Todini and Ciarapica, 2001), a distributed rainfall-runoff model. A detailed description can be found in Liu and Todini (2002). For the implementation of the model over the Reno river basin, the calibration and validation runs have been performed using the hourly meteo-hydrological dataset available from 1990 to 2000 . TOPKAPI is currently employed for operational discharge forecasting by ARPA-SIM (Agenzia Regionale Prevenzione e Ambiente - Servizio Idro Meteorologico), the HydroMeteorological Service of EmiliaRomagna Region.

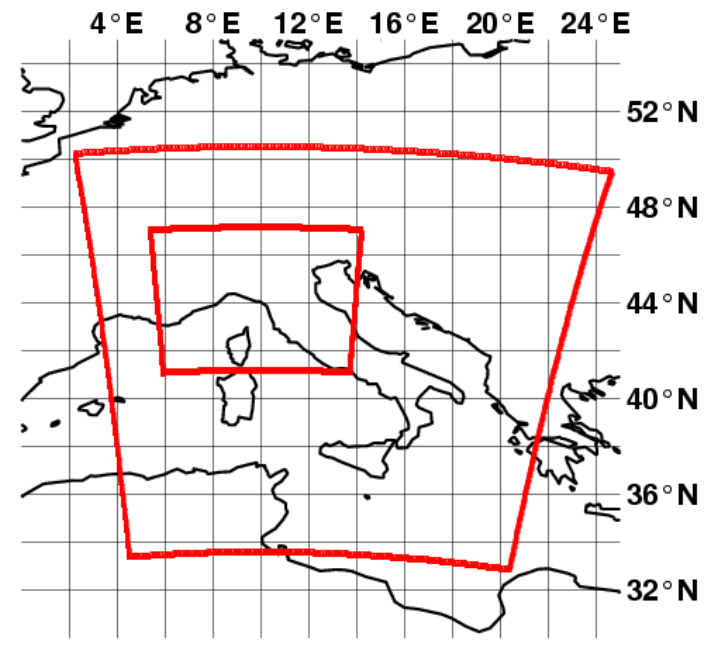

Fig. 2. Model integration domains, the outer (inner) being used for low (high) resolution forecasts.

TOPKAPI is driven by the hourly precipitation provided by several limited-area meteorological models, whose set up is shown in Table 1. BOLAM and MOLOCH models have been developed and implemented by the Institute of Atmospheric Sciences and Climate - National Research Council (ISAC-CNR) in Bologna. A detailed description can be found respectively in Davolio and Buzzi (2004) and Davolio et al. (2007). The Weather Research and Forecasting (WRF) Model (Klemp et al., 2000; Michalakes et al., 2004; Skamarock et al., 2005) has been implemented by ISACCNR in Lecce and is described in the WRF model website (www.wrf-model.org). COSMO model (formerly known as Lokal Model and here referred to as LM) has been implemented by ARPA-SIM. For a complete description of LM, the reader is referred to the COSMO (COnsortium for Smallscale MOdelling) web site (www.cosmo-model.org).

All the models are non-hydrostatic, except for BOLAM, with horizontal resolution ranging from 2.5 to $8 \mathrm{~km}$. For the low resolution integrations, moist convection is parameterized. BOLAM implements the Kain-Fritsch (Kain, 2004) convective scheme. The same scheme, but with some modification is used by WRF. LM implements the Tiedtke massflux scheme (Tiedtke, 1989). At higher resolution, deep moist convection parameterization is switched off in all the models (MOLOCH, WRF and LM).

Model integration domains are shown in Fig. 2. For the coarse resolution run, initial conditions are provided by the operational ECMWF analysis, while boundary conditions are provided every $3 \mathrm{~h}$, over the outer domain, by the ECMWF operational forecasts. The high resolution simulations, provided by nesting as described in Table 1, are performed over the inner domain shown in Fig. 2. In this case, for simulations using one-way nesting, the boundary conditions are updated hourly. This implementation is therefore equivalent to a real-time forecasting system. 
Table 1. Summary of model configurations.

\begin{tabular}{lccccc}
\hline MODEL & Horizontal Resolution $(\mathrm{km})$ & Grid points & Levels & Initial/boundary conditions & Nesting Procedure \\
\hline BOLAM & 8 & $200 \times 240$ & 42 & ECMWF analyses/forecasts & $/$ \\
MOLOCH & 2.8 & $240 \times 240$ & 50 & BOLAM & 1 -way nesting \\
LM7 & 7 & $234 \times 272$ & 41 & ECMWF analyses/forecasts & $/$ \\
LM2.8 & 2.8 & $246 \times 240$ & 41 & LM7 & 1 -way nesting \\
WRF7.5 & 7.5 & $200 \times 240$ & 42 & ECMWF analyses/forecasts & $/$ \\
WRF2.5 & 2.5 & $244 \times 238$ & 42 & WRF7.5 & 2-way nesting \\
\hline
\end{tabular}

Table 2. List of the meteorological events, maximum precipitation registered by the raingauge network within the Reno river basin and forecast details.

\begin{tabular}{|c|c|c|c|}
\hline Date & Meteorological event & $\begin{array}{l}\text { Max cumulated rainfall } \\
\quad \text { (over Reno basin) }\end{array}$ & Forecast initial time and range \\
\hline 6-7 November 1999 & Intense Alpine orographic cyclogenesis & $117 \mathrm{~mm} / 48 \mathrm{~h}$ & 6 Nov 1999, 00:00 UTC, 48 h \\
\hline 21-23 January 2003 & $\begin{array}{l}\text { Deep trough and cold front progressing } \\
\text { eastward }\end{array}$ & $89 \mathrm{~mm} / 48 \mathrm{~h}$ & 21 Jan 2003, 00:00 UTC, $48 \mathrm{~h}$ \\
\hline 7-9 November 2003 & Retrograde (cold-core) cyclone & $171 \mathrm{~mm} / 48 \mathrm{~h}$ & 7 Nov $2003,12: 00$ UTC, $48 \mathrm{~h}$ \\
\hline 10-12 April 2005 & Alpine orographic cyclogenesis & $135 \mathrm{~mm} / 60 \mathrm{~h}$ & 10 Apr 2005, 00:00 UTC, $72 \mathrm{~h}$ \\
\hline 2-3 December 2005 & $\begin{array}{l}\text { Deep trough and cold front progressing } \\
\text { eastward }\end{array}$ & $137 \mathrm{~mm} / 48 \mathrm{~h}$ & 2 Dec $2005,12: 00$ UTC, $48 \mathrm{~h}$ \\
\hline
\end{tabular}

The performance of the probabilistic coupled system is evaluated over the upper portion (about $1000 \mathrm{~km}^{2}$ ) of the Reno river basin, which is located to the north-eastern slopes of the northern Apennines (Fig. 1). (Hereafter with "Reno river basin" we refer only to this upper zone of the entire watershed). The closure section of this mountainous basin, Casalecchio Chiusa, is characterized by a concentration time of about $10-12 \mathrm{~h}$.

In the operational practice, a flood event at such river section is defined when the water level, recorded by the gauge station, reaches or overcomes the value of $0.8 \mathrm{~m}$ (corresponding to a discharge value of about $80 \mathrm{~m}^{3} / \mathrm{s}$ ), corresponding to the warning threshold. The alarm level is set to $1.6 \mathrm{~m}$ (corresponding to a discharge value of about $630 \mathrm{~m}^{3} / \mathrm{s}$ ).

We should keep in mind that some weaknesses are present in our analysis. First, the statistics is limited to just five cases and thus the number of experiments is too small to infer a general conclusion, although covering a range of typical meteorological situations for northern Apennines. The ensemble is not homogeneous, due to different modelling systems and boundary conditions employed. In fact, RAMS, instead of WRF, was included in the two cases shown in Diomede et al. (2008): RAMS was set up differently with respect to the horizontal resolution, the grid domain extension and the number of vertical levels. Also, the ECMWF operational model forecasts have been provided as boundary conditions, in order to simulate a real-time forecasting, in all the events except for the case of 6-7 November
1999, where the 6-hourly reanalysis fields and intermediate 3-hourly fields, provided by the ECMWF 4D-VAR trajectories, have been chosen. Finally, the limitations due to the small number of ensemble members and to the few sources of errors considered in the ensemble generation could produce a limited spread and reduce the performance of the hydrometeorological modelling system.

\section{Results}

The proposed multi-model approach to QPF has been implemented in five episodes of intense precipitation, associated with remarkable river flow increasing (Table 2). These episodes are representative of three different kinds of weather systems that can affect northern Apennines and in particular the Reno river basin.

Alpine orographic cyclogenesis is a quite typical meteorological configuration especially in autumn and spring. The interaction between a baroclinic wave and the Alpine chain favours the development of a secondary cyclone on the lee side (south) of the Alps (Buzzi and Tibaldi, 1978). The cyclonic circulation around the orographic low, that progressively intensifies and moves south-eastward, can affect the northern Apennines with precipitation that can sometimes be intense. Another typical meteorological condition is represented by the passage of a deep trough over the Mediterranean basin, associated to a cold front progressing eastward 


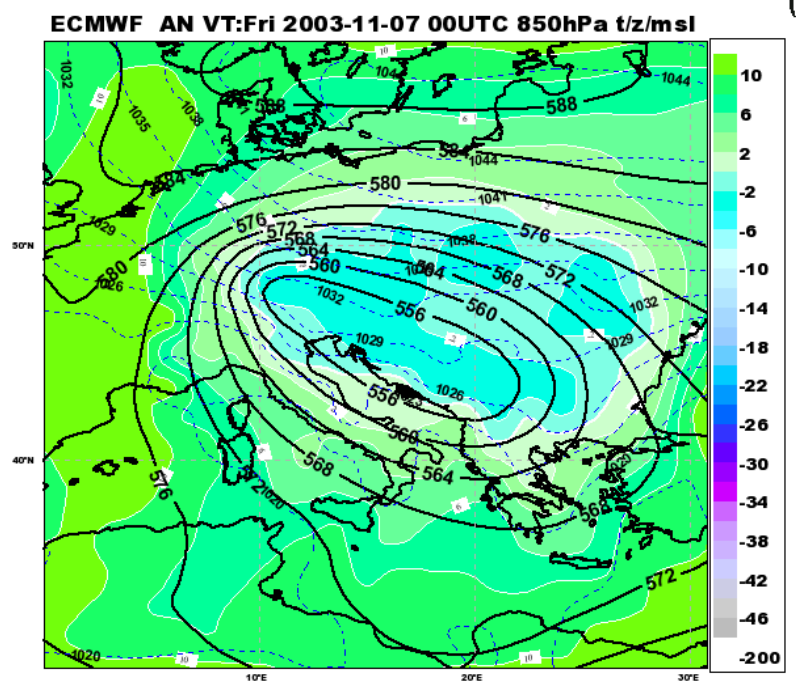

(a)
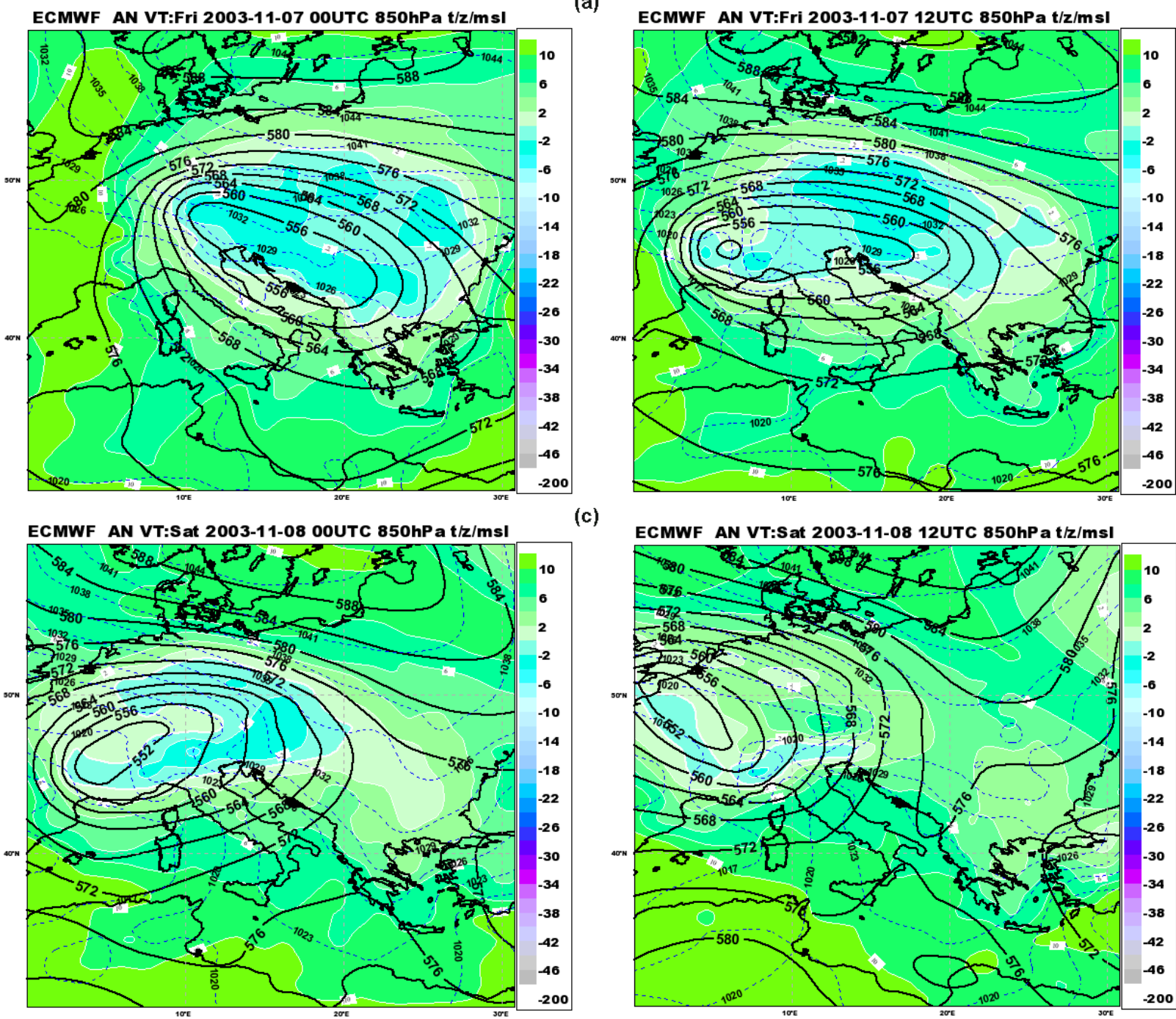

(c)

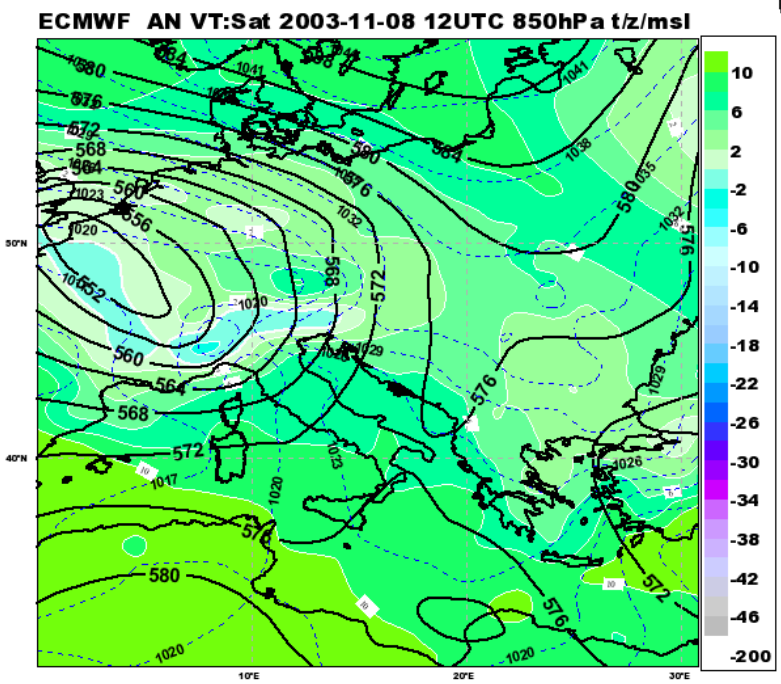

(d)

Fig. 3. ECMWF analyses of geopotential at $500 \mathrm{hPa}$ (black isolines, contour interval $40 \mathrm{gpm}$ ), temperature at $850 \mathrm{hPa}$ (colors) and mean sea level pressure (dashed lines, contour interval $3 \mathrm{hPa}$ ) for 7 Nov 2003 at (a) 00:00 UTC, (b) 12:00 UTC and for 8 Nov 2003 at (c) 00:00 UTC, (d) 12:00 UTC.

quite rapidly. During the autumn and winter seasons, this configuration can produce intense, although not long-lasting, rainfall over the Apennines, due to the rapid movement of the frontal system. Finally, the case of the retrograde cold-core cyclone, that is a cyclonic disturbance at mid troposphere moving westward over northern Italy, is not a very common situation, but it is very interesting since it is associated with severe weather.

The first two episodes in Table 2 have been already described and analysed in Diomede et al. (2008) and will be considered here only in the final discussion. The other three selected flood events, corresponding to three different meteorological conditions, will be thoroughly analysed. Forecasted discharges have been compared to calculated discharges, the latter obtained using observed meteorological data as input and the same set up applied in the forecasting system for the hydrologic model. To obtain the calculated discharge, the Thiessen Polygon method has been employed to spatially distribute the observed precipitation. This procedure can be affected by an intrinsic limitation, since it could distribute the rainfall over a too wide area, especially for isolate measurements located in mountainous region, causing an unrealistic overestimation of the total amount of rainfall. Nevertheless, the calculated curve, instead of the observed discharge, has been used for comparison with the results derived from the meteorological models so that the systematic error of the hydrological model would not affect the comparison. On the other hand, the rainfall fields predicted by the 

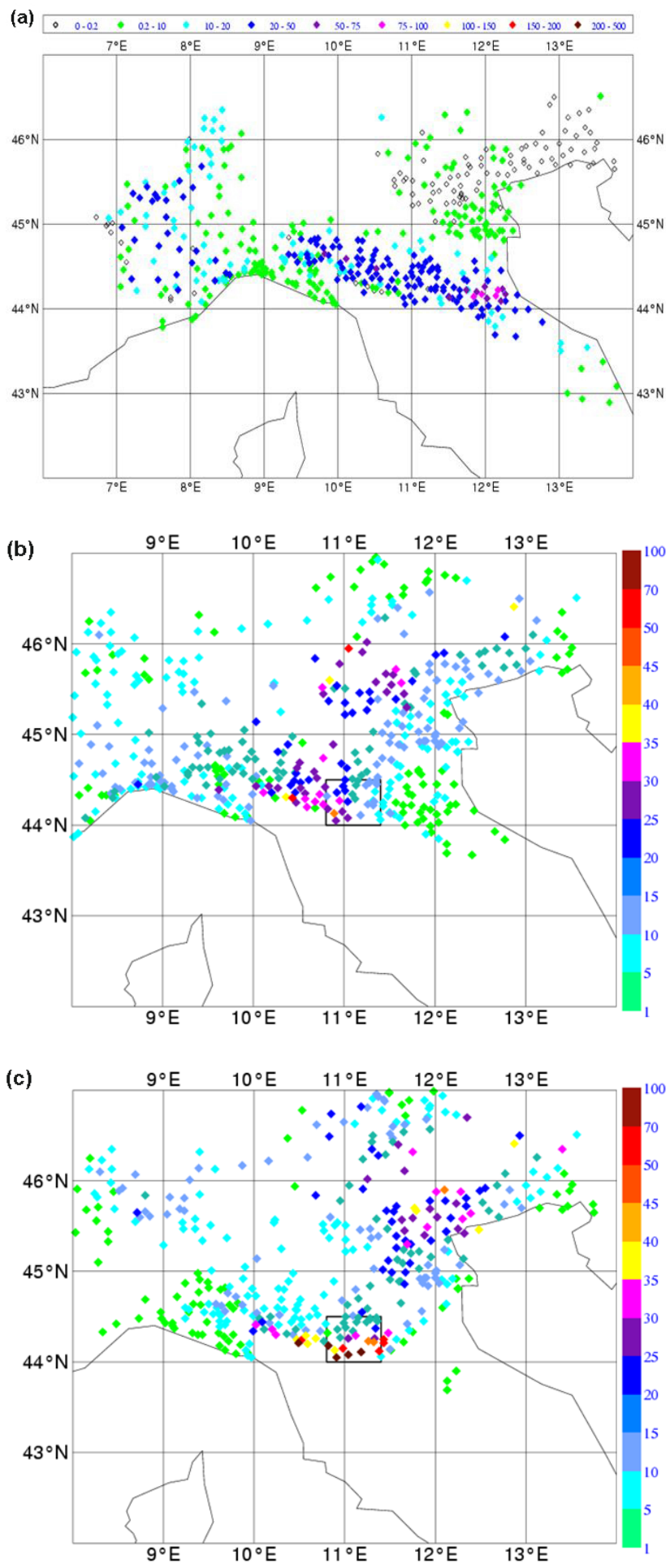

Fig. 4. Observed precipitation (mm). (a) 24-h accumulated rainfall during 7 Nov 2003; 6-h accumulated rainfall between (b) 06:0012:00 UTC and (c) 12:00-18:00 UTC, 8 Nov 2003. The square indicates the upper portion of the Reno river basin. different meteorological models were down-scaled to the hydrological model grid resolution by assigning to each cell the rainfall value provided on the nearest meteorological model grid point.

\subsection{First case study: 7-9 November 2003}

\subsubsection{Meteorological features}

The episode occurred from 7 to 9 November 2003 was associated with a westward moving cyclone. The maximum observed water level for this event was $1.75 \mathrm{~m}$, corresponding to the 13th most intense event recorded in the basin ${ }^{1}$. The ECMWF analysis of 7 November 2003, 00:00 UTC, shows a $500 \mathrm{hPa}$ cut-off low, with a cold core at $850 \mathrm{hPa}$, centred over Croatia, so that the associated cyclonic circulation affected mainly the Adriatic and the Balcanic regions (Fig. 3a). The main axis of the elliptical isolines surrounding the closed minimum was elongated in WNW-ESE direction, from Germany to Turkey. In the following $12 \mathrm{~h}$ the cut-off cyclone moved westward and a closed minimum of about $5520 \mathrm{gpm}$ was located over the western Alps (Fig. 3b). At the same time, the associated trough rotated anticlockwise. During 8 November 2003, the westward movement of the minimum and its anticlockwise rotation continued (Fig. 3c). At 12:00 UTC, the centre of the cyclone was located over northern France and a trough, elongated from NW to SE, crossed northern and central Italy (Fig. 3d). At low levels, a high pressure area over Scandinavia produced an intense easterly flow over northern Italy.

The analysis of the raingauge recordings allows to identify two distinct periods of precipitation. During the first phase, mainly on 7 November, the low level easterly flow impinged on the Apennines producing a wide area of intense rainfall: a maximum larger than $75 \mathrm{~mm} / 24 \mathrm{~h}$ was recorded at some stations in the southern part of the Emilia-Romagna region (Fig. 4a). Simultaneously, precipitation affected the Piedmont region, close to the western Alps. Such distribution of rainfall, concentrated mainly on the side of the mountains that is upstream with respect to the prevailing low level easterly winds, can be considered as a fingerprint of the stable orographic precipitation mechanism working during this phase. Later, in the morning of 8 November (Fig. 4b), the largest precipitation amount was recorded along a narrow band, extended from Veneto to Emilia-Romagna region (data over Tuscany are not available). In the following $6 \mathrm{~h}$, the band shifted further eastward, affecting the plains of northeastern Italy (Fig. 4c). During the 12-h period between 06:00 and 18:00 UTC of 8 November, heavy rainfall insisted mainly over the Reno river basin, exceeding $100 \mathrm{~mm} / 12 \mathrm{~h}$ at several locations. The origin of the rainfall during this phase can be attributed to the passage of the upper level trough over

\footnotetext{
${ }^{1}$ The historical archive of flood events covers the period between 1981 and 2004.
} 
the area (Fig. 3) associated with the meridional wind impinging over the Apennines.

\subsubsection{Observed and forecast precipitation}

The observed and forecast $6 \mathrm{~h}$-accumulated precipitation, averaged over the Reno river basin, are shown in Fig. 5a. It is apparent that the maximum precipitation was recorded in the second part of the event, from 12:00 to 18:00 UTC, 8 November (corresponding to the $24-30 \mathrm{~h}$ forecast range in Fig. 5a), when the rainfall peak was larger than $40 \mathrm{~mm} / 6 \mathrm{~h}$. None of the models did predict correctly the temporal evolution of the event, as they largely overestimated the rainfall during the first phase (00-12 h forecast range) and most of them missed completely the peak in the second part.

The hourly cumulated rainfall, shown in Fig. 5b, allowed a more detailed intercomparison among the rainfall predictions and the observations. During the first phase, on 7 November, all the members of the ensemble remained very close each other, although largely above the observed curve. Thus, the ensemble was not able to provide a reliable estimation of the meteorological uncertainty, due to the considerable underdispersion, i.e. insufficient spread among the members. This behaviour was found for very short range forecasts and medium-sized river basins also by Hou et al. (2007). Moreover, the similar and incorrect behaviour held by the different meteorological models at such a short forecast range suggests that probably the initial and boundary conditions provided to the models were inaccurate. Depending on the large-scale flow, the initial and boundary conditions may exert a noticeable influence on the forecast, so that they can induce a considerable amount of error into the meteorological simulations and, consequently, in the hydrological application. A more comprehensive approach would have included in the ensemble also the uncertainties associated with the initial and boundary conditions (multi-model, multi-analysis approach), but the application of this technique is out of the purposes of the present paper.

On 8 November, all the models strongly underestimated the observed cumulated rainfall (Fig. 5b). The sharp precipitation increase observed from 12:00 to 18:00 UTC (24-30 h forecast range), was reproduced approximately well only by MOLOCH, although underestimate and with nearly 6 hours of delay. From Fig. 5b it is apparent that, in general, the higher resolution simulations improved the rainfall predictions with respect to the coarser resolution runs since also LM2.8 shows a small precipitation increase with the same delay. Only for WRF the improvement was negligible, since both the WRF runs missed almost completely the steep rainfall increase. The 2-way nesting technique probably suppressed the differences between the finer and the coarser runs.
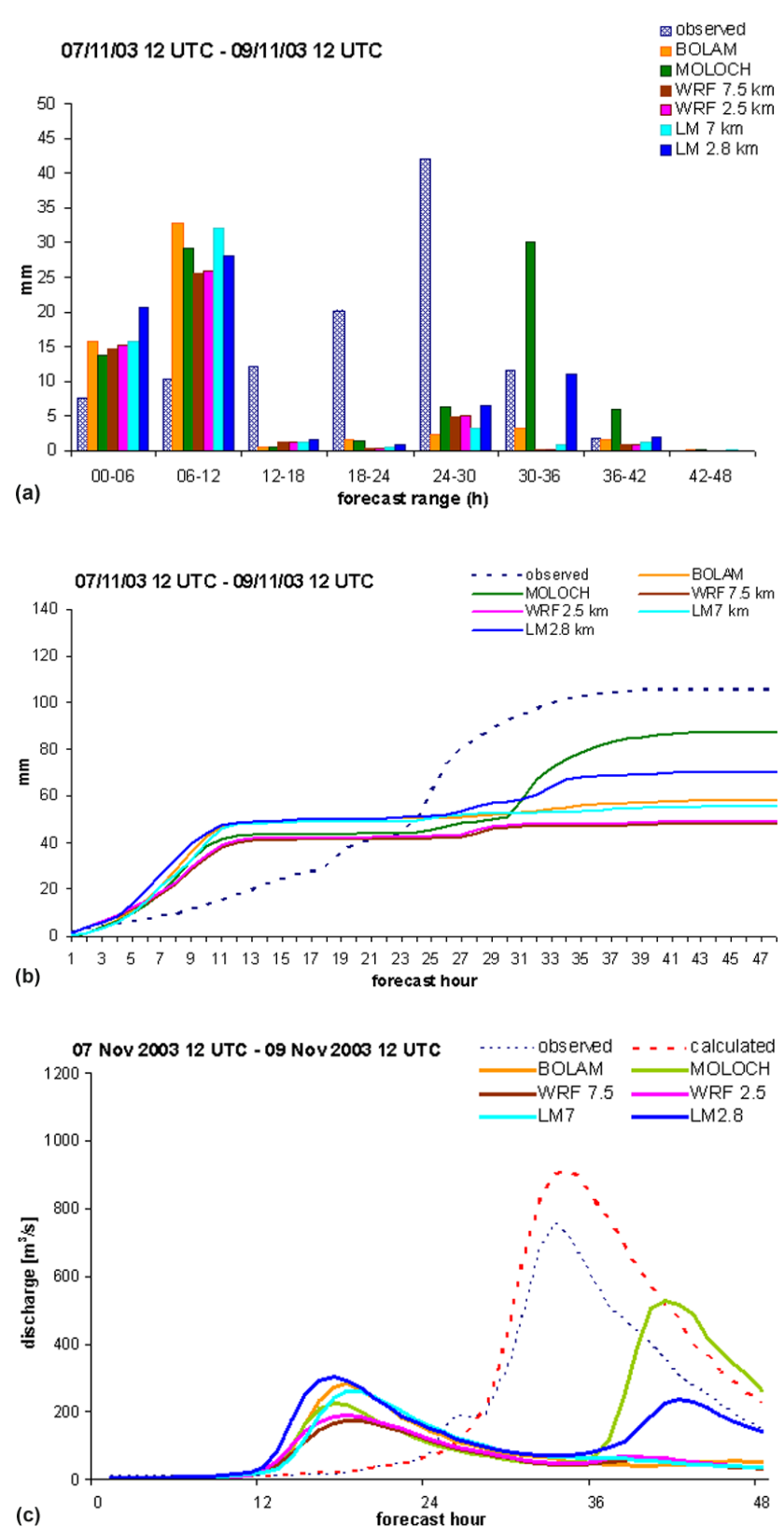

Fig. 5. 7-9 Nov 2003 event. (a) $6 \mathrm{~h}$ observed and forecast precipitation ( $\mathrm{mm}$ ) averaged over the Reno river basin. (b) Precipitation $(\mathrm{mm})$ averaged over the Reno river basin cumulated from the beginning of the forecast, using hourly data. (c) Discharge forecast $\left(\mathrm{m}^{3} / \mathrm{s}\right.$ ) vs. forecast range (h). In (c), the different curves have been obtained by feeding the TOPKAPI model with the precipitation forecast by the different meteorological models and with the raingauge observations (red dashed line). The observed discharge (blue dotted line) is also plotted for reference. 


\subsubsection{Observed and forecast discharge}

Figure $5 \mathrm{c}$ shows the measured, the calculated and the predicted discharges vs. forecast time. A discharge quite similar to the observed one, but with a slight overestimation of the peak and the descending curve, was obtained by feeding the hydrological model with raingauge measurements, spatially distributed by the Thiessen Polygon method. The river flow increased after 06:00 UTC, 8 November, reaching the maximum discharge (about $900 \mathrm{~m}^{3} / \mathrm{s}$ ) during the night, at approximately 22:00 UTC of 8 November. Then the flow decreased, as a consequence of the reduced amount of precipitation.

The response of the hydrological model was completely different when it was forced with the forecast precipitation. This discrepancy among the discharges predicted by the different hydrological forecast and the calculated discharge based on the observed rainfall is a consequence of the fact that all the meteorological model simulations were affected by errors both in terms of timing and amount of rainfall over the Reno river basin, as shown in Fig. 5a and b. All the simulations produced a peak of discharge during the phase of orographic precipitation, ranging from less than $200 \mathrm{~m}^{3} / \mathrm{s}$ (WRF) to about $300 \mathrm{~m}^{3} / \mathrm{s}$ (LM2.8), while the observed discharge did not show any increase in this phase. On the opposite, all the simulations missed the observed peak, recorded during the transit of the trough; only MOLOCH and LM2.8 were able to produce a peak in this phase, but with a delay of about $6 \mathrm{~h}$ and a significant underestimation with respect to the calculated discharge (the forecast peak is $500 \mathrm{~m}^{3} / \mathrm{s}$ and $200 \mathrm{~m}^{3} / \mathrm{s}$ for MOLOCH and LM2.8, respectively).

\subsubsection{Further analysis}

In order to better understand the reasons for the failure of the models, it seems necessary to investigate more in detail the distribution of the predicted rainfall in the region. The precipitation forecasts were evaluated over an area larger than the Reno river basin, which is too small to provide a general view of the meteorological models' performance. We will concentrate mainly on the time interval from 12:00 to 18:00 UTC, 8 November, during the period of the maximum observed precipitation in the basin and of the largest model errors. During this phase, the observations showed two different areas of intense rainfall (see Fig. 4c): the former was located over the Apennines between Tuscany and EmiliaRomagna regions, with a maximum rainfall of more than $70 \mathrm{~mm} / 6 \mathrm{~h}$ registered in some stations in the upper part of the Reno river watershed; the latter was located north of the Po mouth, close to the Adriatic coast of Veneto region.

Figure 6a shows the distribution of the precipitation field for WRF2.5: an area of intense rainfall, of similar intensity to that one observed in the basin, was centred close to, but outside, the Reno watershed. The fact that the rainfall was shifted a few tents of kilometres to the west made the hydrological prediction completely wrong although the meteoro- logical forecast, both in terms of rainfall amount and timing of the event, can be considered quite satisfactory, since it is indicative of intense precipitation over the northern Apennines area. In the following $6 \mathrm{~h}$, the rainfall moved further north-eastward, far from the basin (Fig. 6b). Similar results came out for the WRF coarse resolution run (not shown).

Also LM2.8 predicted the location of the rainfall maximum out of the basin (Fig. 6c). However, differently from WRF, the rainfall persisted over the Apennines during the following $6 \mathrm{~h}$ interval so that a maximum of about $45 \mathrm{~mm} / 6 \mathrm{~h}$ was recorded in the Reno river basin from 18:00 UTC, 8 November, to 00:00 UTC, 9 November (Fig. 6d). In that period, the $6 \mathrm{~h}$-cumulated LM2.8-forecast precipitation, averaged over the basin, agreed well with the observed value (Fig. 5a). The rainfall predicted by LM7 (not shown) was much smaller than the LM2.8 forecast (Fig. 5a, b).

Compared with LM2.8 and WRF, the rainfall maximum predicted by MOLOCH in the northern Apennines from 12:00 and 18:00 UTC was significantly smaller (Fig. 6e). In the following $6 \mathrm{~h}$, the rainfall was distributed along a band elongated from the Apennines to Veneto; a large peak of $83 \mathrm{~mm}$ was observed in the mountainous part of the Reno basin and in most of the watershed the predicted rainfall was larger than $20 \mathrm{~mm}$ (Fig. 6f), explaining the large discharge peak observed during this phase (Fig. 5c). BOLAM precipitation forecast was affected by a large underestimation during the entire period of interest (not shown).

In summary, the models predicted the general rainfall pattern quite well, although with some significant differences with respect to the observations. The results proved that the hydrological response of the Reno medium-sized catchment, modelled by the distributed rainfall-runoff model TOPKAPI, is highly dependent not only on the rainfall amount and timing, but also on the correct localization of the precipitation.

\subsection{Second case study: 10-12 April 2005}

\subsubsection{Meteorological features}

The analysed period was characterized by the rapid development of an orographic cyclone south of the Alps and the passage of a frontal system over northern Italy. During the 9 April, a wide depression area, with several pressure minima, affected the Scandinavian Peninsula, while an intense trough, elongated in a northeast-southwest direction, moved over France, towards the Mediterranean basin. At upper level, a PV streamer was associated with the trough (not shown).

In the following $48 \mathrm{~h}$ a cyclogenesis occurred over the Mediterranean. During the first hours of 10 April (Fig. 7a) a lee cyclone appeared over the Mediterranean sea, west of Corsica, underneath the mid tropospheric trough and in the following hours it deepened moving slowly southward over Sardinia. The intensification of the orographic depression was favoured by the cold air outbreak at upper levels $\left(-32^{\circ} \mathrm{C}\right.$ at $\left.500 \mathrm{hPa}\right)$ over western Mediterranean and as a 

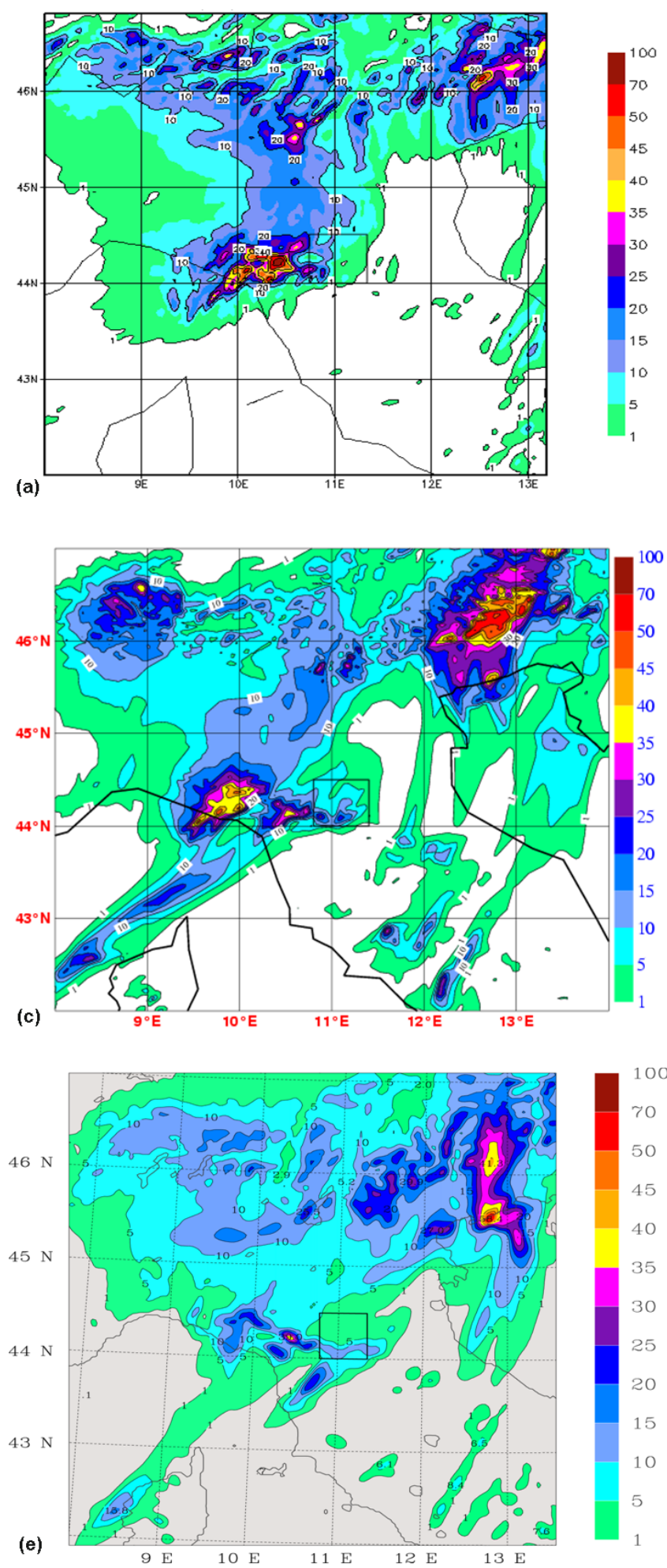
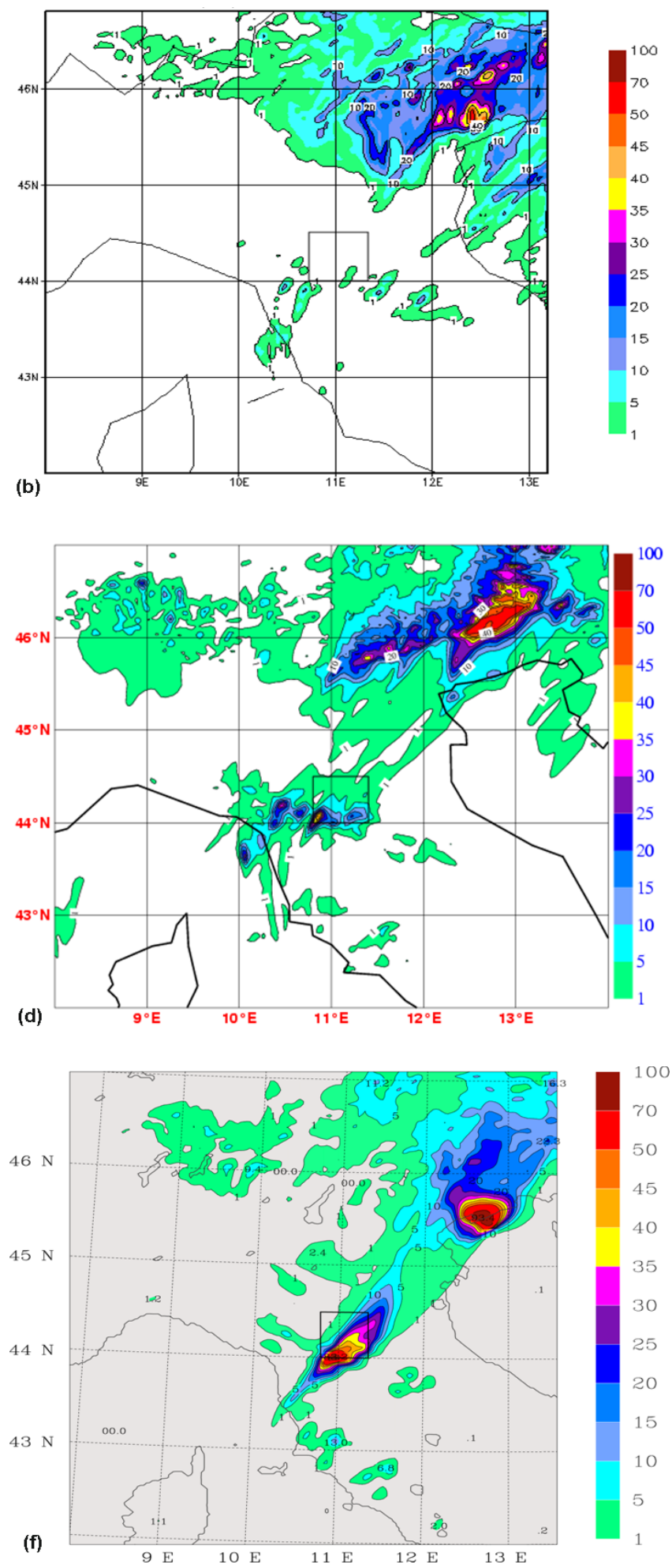

Fig. 6. 6-h accumulated precipitation at 18:00 UTC, 8 Nov 2003 (a, c, e) and at 00:00 UTC, 9 Nov2003 (b, d, f) as forecasted by WRF2.5 (a, b), LM2.8 (c, d) and MOLOCH (e, f). 


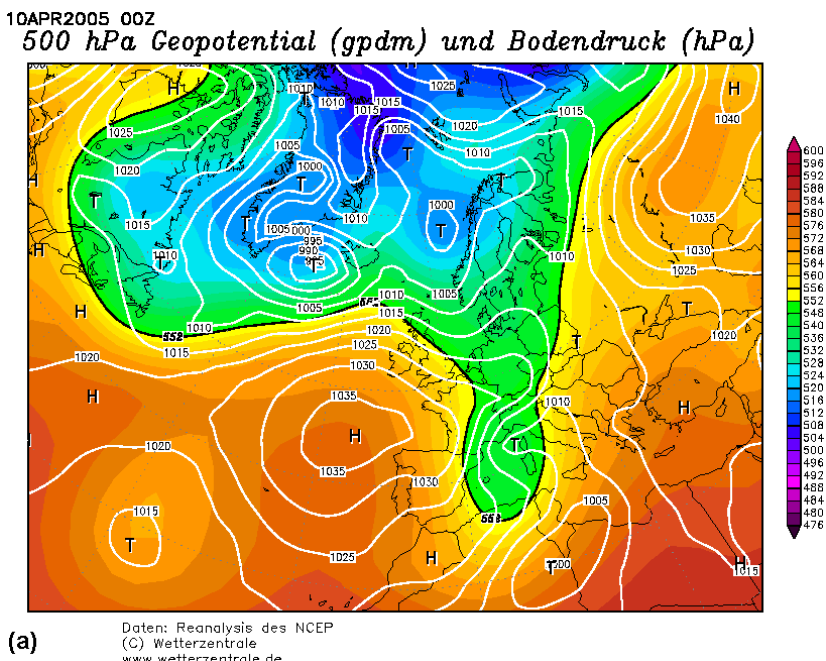

Daten: Reanalysis des
(a) Wetterzentrale
www wetterzentrale, de

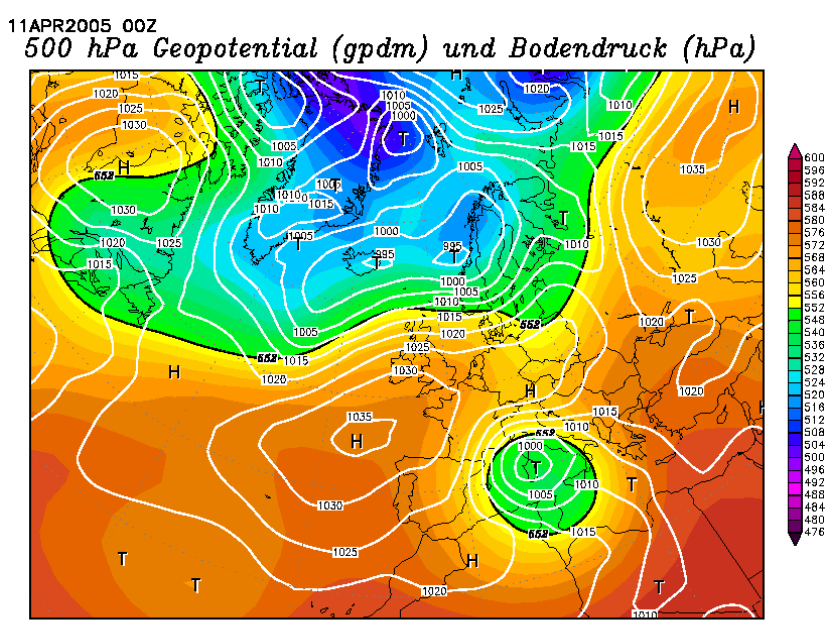

(b) Daten: Reanolysis des NCEP
(C) Wetterzentrale
www wetterzentrale, de

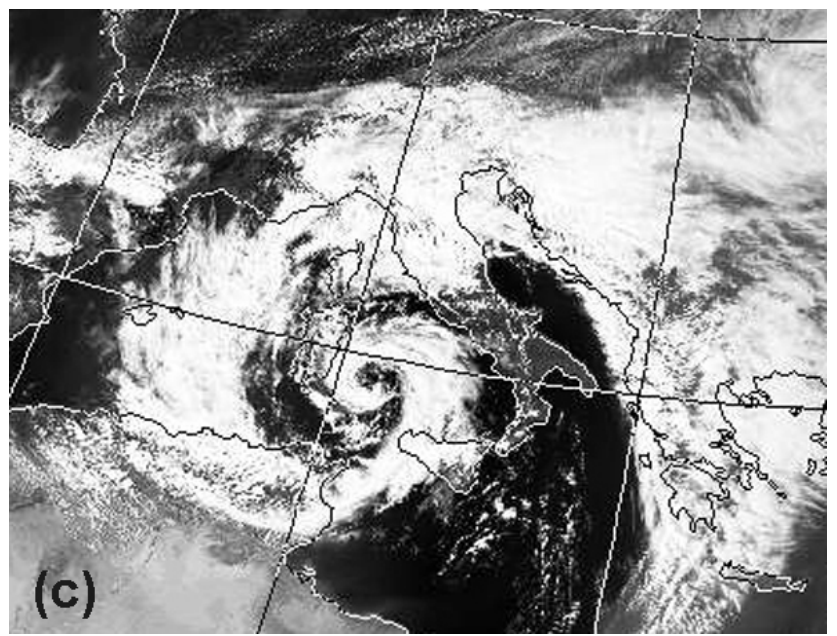

Fig. 7. NCEP reanalysis for (a) 10 April 2005 at 00:00 UTC, (b) 11 April 2005 at 00:00 UTC: geopotential at $500 \mathrm{hPa}$ (colors) and mean sea level pressure (isolines, contour interval $5 \mathrm{hPa}$ ). (c) AVHRR visible image at 13:28 UTC, 11 April 2005. consequence of the interaction and merging with a surface disturbance (visible in Fig. 7a) coming from northern Africa. The upper level trough extended towards northern Africa, producing a warm south to south-westerly flow over southern and central Italian Peninsula. At the same time, another cold air outbreak from the north-east affected the northern Adriatic with strong Bora-type flow which favoured the precipitation on the windward (northern) side of the Apennines and in particular over the Reno river basin.

During the morning of 11 April, the lee cyclone appeared fully developed with a minimum pressure of $998 \mathrm{hPa}$ close to Sardinia (Fig. 7b) and it was well separated by the "parent" cyclone over the Norwegian sea by a strong pressure ridge north of the Alps. The cut-off was well developed at all levels, and also the PV streamer completed the cut-off process in the course of the afternoon. The cyclonic circulation affecting the Mediterranean basin still favoured the persistence of north-easterly flow impinging on the northern Apennines, responsible for cloudiness (Fig. 7c) and further moderate precipitation over the analysed basin (Fig. 8a).

\subsubsection{Observed and forecast precipitation}

A detailed analysis of the observed precipitation field indicates that the rainfall over the Reno river basin was particularly intense between 12:00 and 18:00 UTC, 10 April (corresponding to the $12-18 \mathrm{~h}$ forecast range in Fig. $8 \mathrm{a}$ and $\mathrm{b}$ ), with a number of raingauges recording more than $30 \mathrm{~mm} / 6 \mathrm{~h}$, some of them above $40 \mathrm{~mm} / 6 \mathrm{~h}$ (not shown). Also the following 6-h period was characterized by quite intense and widespread precipitation, around $30 \mathrm{~mm} / 6 \mathrm{~h}$ at some stations. Later, during 11 April, the rainfall intensity progressively decreased except for a temporary phase of rainfall intensification between 12:00 and 18:00 UTC. This behaviour is shown also by the hourly cumulated precipitation (Fig. 8b, dashed line) which increased during the first $24 \mathrm{~h}$, then remained nearly constant for many hours, before displaying a further growth approximately $36 \mathrm{~h}$ after the beginning of the episode.

Although underestimating the main precipitation peak, all the models predictions reproduce quite well the behaviour of the rainfall field averaged over the basin (Fig. 8a), especially during the first $24 \mathrm{~h}$. During the first $12 \mathrm{~h}$ of 11 April (24-36 $\mathrm{h}$ forecast range), the models tend to overestimate the rainfall, while in the following $12 \mathrm{~h}$ a progressive weakening of the precipitation, instead of a second, minor peak, is forecast. However, the hourly cumulated precipitation, averaged over the basin (Fig. 8b) shows a remarkably good agreement between observations and forecasts over the entire period.

\subsubsection{Observed and forecast discharge}

As it is reasonable to expect from the above evaluation, the discharge predicted by the hydrological model fed with observed precipitation presents two peaks (Fig. 8c). The first peak of about $360 \mathrm{~m}^{3} / \mathrm{s}$ was attained in the early morning of 
11 April, followed by a second weaker discharge maximum of about $230 \mathrm{~m}^{3} / \mathrm{s}$ during the following night. The computed discharge is in good agreement with the observed one (maximum observed streamflow of about $345 \mathrm{~m}^{3} / \mathrm{s}$, corresponding to the 50th most intense event recorded in the basin), the latter displaying also two peaks of similar magnitude, but a more pronounced decreasing phase between them.

Discharges based on rainfall observations and on different meteorological model inputs display quite different behaviour in terms of hydrological forecasts. The discharge forecasts driven by LM at both high and low resolution, reproduce accurately the timing and intensity of the first discharge peak, but in the following, tend to overestimate the river flow displaying a steadily decrease of the flow, according to the progressive ending of the forecast precipitation. Forcing the hydrological model with both WRF rainfall forecasts produces a discharge prediction characterized by a good estimate of the peak intensity, but with a slight (however less than six hours) delay. Moreover, there is also the signature of a second discharge maximum some hours later, whose intensity is remarkably overestimated. This is a consequence of the significant overestimation of the rainfall over the basin during the first twelve hours of 11 April (Fig. 8a). The secondary maximum is properly reproduced by the hydrological forecast driven by both BOLAM and, to some extent, also by MOLOCH. Conversely, both these forecasts are affected by an underestimation of the main discharge peak, which is particularly remarkable in the MOLOCH-based simulation. However, the discharge obtained using BOLAM rainfall reproduces quite accurately the two different phases of the river flow. This behaviour is due to the agreement of BOLAM forecasts with the precipitation recordings shown in Fig. 8a, characterized by weak average intensity in the first half of 11 April (24-36 h forecast range) and a temporary increase in the following hours. As far as MOLOCH forecast is concerned, since the total averaged amount of rainfall over the basin is very close to those of BOLAM (Fig. 8b), the different behaviour in the discharge forecast can be ascribed to a different localization of the rainfall within the Reno river basin.

\subsection{Third case study: 2-3 December 2005}

\subsubsection{Meteorological features}

The third case occurred in the night between 2 and 3 December 2005. The maximum observed water level for this event was $1.64 \mathrm{~m}$, corresponding to the 19th most intense event recorded in the basin. This event was originated by the presence of a deep pressure minimum located over the British Isles. At 00:00 UTC of 2 December, the pressure minimum was about $970 \mathrm{hPa}$. The associated $500 \mathrm{hPa}$ trough was elongated in north-south direction, extending from the North Sea to Algeria, well inland in the African continent. In the following $48 \mathrm{~h}$, the low pressure persisted over the British Is-
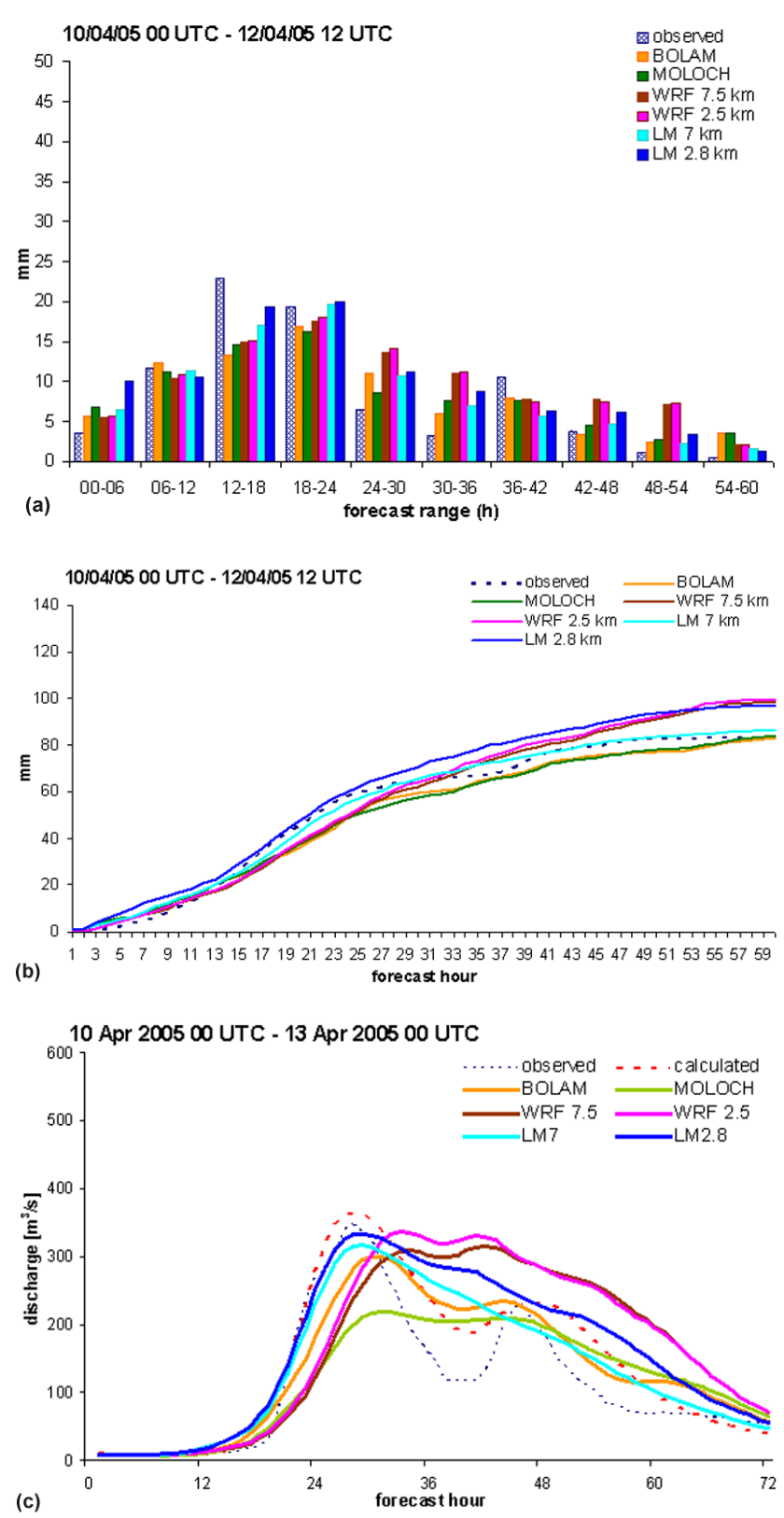

Fig. 8. As in Fig. 5, but for the 10-12 April 2005 event.

lands, since it moved slightly in north-east direction; meanwhile, its minimum value increased only of a few $\mathrm{hPa}$. In the night of 2 December (Fig. 9), the upper level trough progressed eastward and slightly rotated anticlockwise, approaching the northern Italian regions. A shallow surface low, of about $1000 \mathrm{hPa}$, moved toward the Gulf of Genoa. As a consequence of this configuration, intense southerly winds affected northern Italy. 


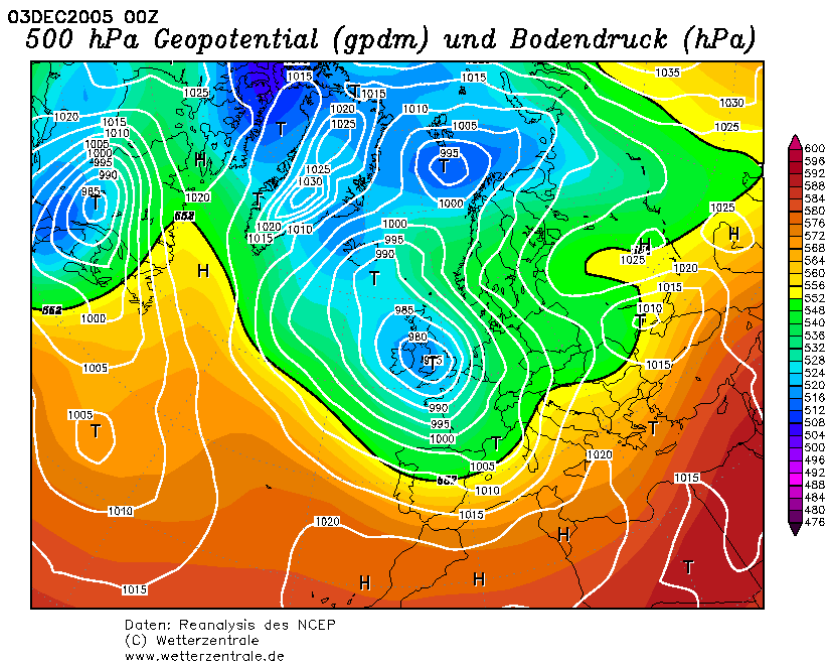

Fig. 9. NCEP reanalysis 3 Dec 2005 at 00:00 UTC: Geopotential at $500 \mathrm{hPa}$ (colors) and mean sea level pressure (isolines, contour interval $5 \mathrm{hPa}$ ).

\subsubsection{Observed and forecast precipitation}

During the fast passage of the minimum and of the associated frontal system over northern Italy, the precipitation affected mainly the northern Apennines, where large values, close to $100 \mathrm{~mm}$ mostly concentrated in $6 \mathrm{~h}$, have been recorded in some stations during the night between 2 and 3 December (not shown). Over the Reno river basin, the precipitation was mainly concentrated in this phase, with an averaged rainfall of about $30 \mathrm{~mm} / 6 \mathrm{~h}$ between 00:00 and 06:00 UTC, 3 December (corresponding to the $12-18 \mathrm{~h}$ forecast range in Fig. 10a). Afterward, the frontal system moved further eastward and affected more directly the north-eastern Italian regions. All the models forecast correctly the total rainfall in the basin (Fig. 10b) and the general rainfall pattern, that produces intense precipitation over the Apennines.

\subsubsection{Observed and forecast discharge}

The discharge calculated by the hydrological model fed with raingauge recordings shows that the river streamflow increased after 00:00 UTC, 3 December (Fig. 10c). The maximum value (of about $850 \mathrm{~m}^{3} / \mathrm{s}$ ) was reached about $12 \mathrm{~h}$ later; then the streamflow decreased, as a consequence of the ending of the precipitation, and turned below $200 \mathrm{~m}^{3} / \mathrm{s}$ at around 00:00 UTC, 4 December. The computed discharge overestimated the observed discharge during the whole duration of the event, in particular close to the peak (about $850 \mathrm{~m}^{3} / \mathrm{s}$ vs. $600 \mathrm{~m}^{3} / \mathrm{s}$ ).

The hydrological forecasts, based on meteorological model inputs, were able to reproduce quite well the shape and the timing of the calculated streamflow, that lies inside the range of the forecast scenarios. With respect to the forecast of the level of alert, the spread among the different mem-
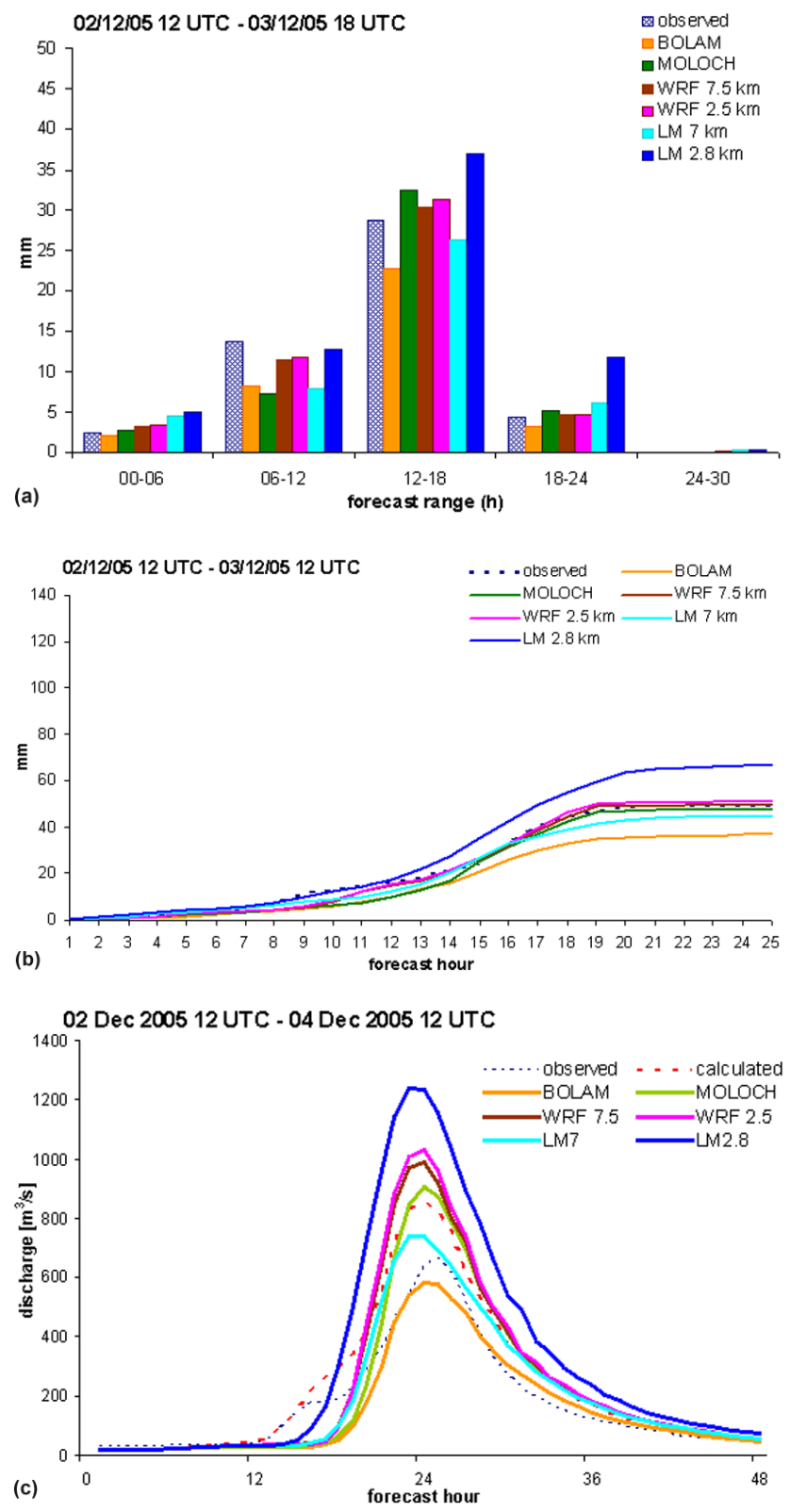

Fig. 10. As in Fig. 5, but for the 2-3 Dec 2005 event.

bers of the ensemble came out to be quite large, since the forecast discharge peaks ranged from $600 \mathrm{~m}^{3} / \mathrm{s}$ (BOLAM) to more than $1200 \mathrm{~m}^{3} / \mathrm{s}$ (LM2.8). Such a large spread can be interpreted as an expression of low predictability for this specific event. However, the fact that each model predicted a discharge larger than or very close to the threshold that delimits the level of alarm $\left(630 \mathrm{~m}^{3} / \mathrm{s}\right)$ would leave no doubts to the authorities in charge of decision about the opportunity of issuing an alarm message for this case. 


\subsubsection{Further analysis}

The differences among the predicted discharges reflect, in first approximation, the rainfall amount forecasted by the different meteorological models over the basin. All the models underestimated the precipitation in the evening of 2 December (Fig. 10b), so that the increase in the calculated discharge at about 00:00 UTC, 3 December (corresponding to the $12 \mathrm{~h}$ forecast range), was delayed of a few hours by each member of the ensemble (Fig. 10c). In the first few hours of 3 December, the rainfall forecast by BOLAM remained much smaller than the observations and consequently, the simulated peak was significantly underestimated. On the opposite, LM2.8 overestimated the rainfall, so that a significant overestimation affected also the discharge peak predicted by this model. MOLOCH, WRF2.5, WRF7.5 and LM7 reproduced pretty well the cumulated rainfall averaged over the basin, so that the predicted discharges fit correctly the calculated discharge. In particular, the four ensemble members converged to the computed curve a few hours after the peak.

A feature which was common to all the modelling systems, apart from WRF, was the fact that the predicted discharge was significantly larger for the higher resolution models compared to the coarser resolution ones. This is a consequence of the rainfall distribution over the catchment, which was concentrated mainly close to the mountains: the high resolution runs tended to produce larger precipitation values in these areas, due probably to the steeper terrain being resolved. Figure 11 shows the rainfall predicted from 00:00 to 06:00 UTC, 3 December, by the BOLAM (Fig. 11a) and MOLOCH (Fig. 11b) models: it is apparent that the rainfall predicted by MOLOCH had a smaller horizontal scale compared with BOLAM, better reflecting the underlying topography. It is interesting to observe that the average accumulated rainfall amounts predicted by the two models (Fig. 10b) were very close each other during the first phase. The curves diverge only after the transit of the frontal system over the basin, when the intense synoptic flow impinged directly on the orography delimiting the basin on its south-western side. The higher resolution of MOLOCH improved significantly the prediction of precipitation with respect to BOLAM, both in terms of average rainfall and of river streamflow. Similarly, the high resolution LM run, compared with the coarse resolution simulation, produced larger rainfall but, differently from BOLAM-MOLOCH, degraded the quality of the forecast, largely overestimating the orographic precipitation in the basin. Finally, in WRF, due to the 2-way nesting procedure, the inner domain influenced the outer one and the difference between the high and low resolution fields was much smaller.
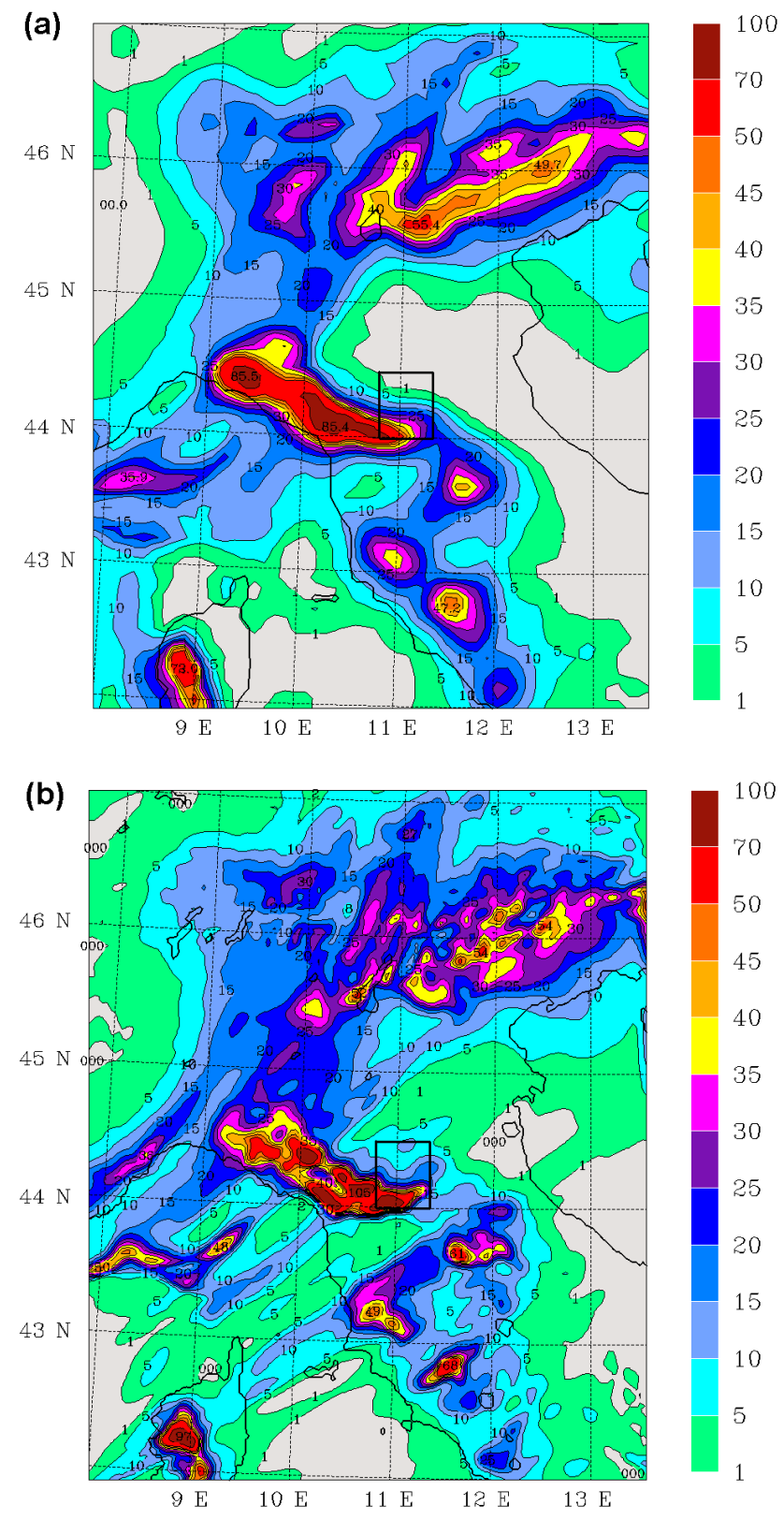

Fig. 11. 6-h accumulated precipitation at 06:00 UTC, 3 Dec 2005 forecasted by (a) BOLAM and (b) MOLOCH models.

\section{Application to operational discharge forecasting}

In the present Section, some considerations are drawn about the ability of the meteo-hydrological multi-model system to produce relevant information concerning the prediction of discharges. In such an effort, the simulated discharges are compared with the calculated streamflow for the three case studies shown in the present paper and for the two events discussed in Diomede et al. (2008). The five events are grouped in three subsets, as shown in Table 2, corresponding to three different weather situations. 
The purpose of the present analysis is to evaluate the usefulness of the modelling system for operational forecasting applications, assessing its ability to provide more informative hydrological prediction through the estimation of the uncertainty associated with the meteorological models. Decision makers, final consignee of the forecasting procedure results, have recently realized the value of a forecast that includes the estimate of its uncertainty (Siccardi et al., 2005). In particular, a suitable forecasting tool should be able to discriminate among the threshold for warning $(0.8 \mathrm{~m}$ for the Reno river basin, corresponding to about $\left.80 \mathrm{~m}^{3} / \mathrm{s}\right)$ and for alarm $(1.6 \mathrm{~m}$, that is about $630 \mathrm{~m}^{3} / \mathrm{s}$ ) in order to allow the authorities in charge of decision to take the most appropriate actions.

The comparison is performed considering the discharge forecast issued by the ensemble mean as the best forecast and representing the range of the possible outcomes, that is the ensemble forecast uncertainty, as the interval extending between the 10th and the 90th percentile (respectively, P10 and $\mathrm{P} 90$ hereafter).

The two cases of Alpine orographic cyclogenesis are analysed first. For both the events, the peak of calculated discharge is relatively small, about $400 \mathrm{~m}^{3} / \mathrm{s}$. In the event of 6-7 November 1999 (Fig. 12a), the ensemble mean forecast discharge is affected by a delay of several hours with respect to the increase of the computed streamflow, so that the observed peak is not exactly reproduced both in terms of timing (about $6 \mathrm{~h}$ delay) and discharge amount (underestimation). The range P10-P90 lies below the calculated discharge and only at the end of the event the ensemble mean get closer to the observations and the calculated discharge is included in the range of the ensemble forecast. However, from the user perspective, the forecast is quite good, since the event intensity is well predicted and the timing error is not crucial with respect to the involved forecast time range $(+24-48 \mathrm{~h})$. In the case of 10-12 April 2005 (Fig. 12b), the streamflow main peak is more correctly reproduced: the ensemble mean underestimates the peak only slightly and shifts its occurrence of just a few hours. Although the time evolution of the mean discharge does not agree exactly with the observation (it misses the decrease between the two peaks) the computed discharge is encompassed by the P10-P90 range for most of the time. Again, the hydrological forecast turns out to be useful for warning purposes.

Then, we pass to consider the two cases of deep trough and cold front progressing eastward. For the event of 2-3 December 2005 (Fig. 12c), the calculated flow peak is about $850 \mathrm{~m}^{3} / \mathrm{s}$. The ensemble mean curve remains very close to the calculated discharge, except for a few hour delay of the ascending curve, that is not reproduced by any member of the ensemble. The spread is wide, especially around the peak, and distributed almost symmetrically with respect to the computed curve, as a consequence of the accurate temporal phase of the forecast. However, the ensemble result would leave no doubt to the decision makers to issue a flood alert, as stressed also in the previous Section, since the P10-P90 range of peaks lies almost completely above the threshold of $630 \mathrm{~m}^{3} / \mathrm{s}$. During the event of January 2003 (Fig. 12d), the streamflow peak is less intense (about $400 \mathrm{~m}^{3} / \mathrm{s}$ ): on average, the magnitude was predicted pretty well even if the P10-P90 range lies under the calculated discharge and the temporal occurrence of the event is weakly delayed. The spread is not large enough to completely include the observed peak, but the error is small and not crucial for warning purposes.

Finally, for the case of retrograde (cold-core) cyclone of 7-9 November 2003 (Fig. 12e), the ensemble mean completely misses the event due to the wrong temporal phase and the large underestimation the individual members showed (Fig. 5c). The ensemble mean displays a low peak, missing the observation in the first phase, while the observed maximum is largely underestimated and delayed of several hours. Neither the P90 curve would have given indication for issuing an alert for this event.

In conclusion, the information conveyed by the multimodel system come out to be useful with respect to its potential operational application. In four out of the five cases analysed here, the predictions agree pretty well with the observations. For the purposes of discharge prediction, it is relevant to observe that a suitable alert message (warning for three events, alarm for one case) would have been issued with a sufficient lead time. Only in the case of retrograde cyclone the modelling system does not predict correctly the intensity of the event and, based on the ensemble outputs, an ordinary warning would have been emitted instead of a message of alarm. Although a few case studies do not obviously provide a sufficient basis for general conclusions, the presented results point to the potential of the multi-model system to represent uncertainty on scales which are relevant for hydrological applications.

\section{Conclusions}

In the present work, a multi-model approach to QPF has been implemented in order to provide an ensemble of hydrological forecasts and has been tested on five episodes of intense precipitation, associated to streamflow increasing of different intensity. The meteorological events span three different weather situations generally affecting northern Apennines and bearing intense rainfall over the Reno river basin in northern Italy. The estimation of the uncertainty associated with the high resolution meteorological prediction conveyed by the multi-model ensemble is then exploited by the meteo-hydrological modelling chain, propagating it into the discharge forecast.

For all the analysed events, the spread of the discharge ensemble seems to be adequate to convey a quantification of the discharge forecast uncertainty, useful to support civil protection authorities in their decisions. Indeed, the occurrence of the flood episodes is properly predicted with a sufficient lead time, the timing error being not crucial with respect 
(a)

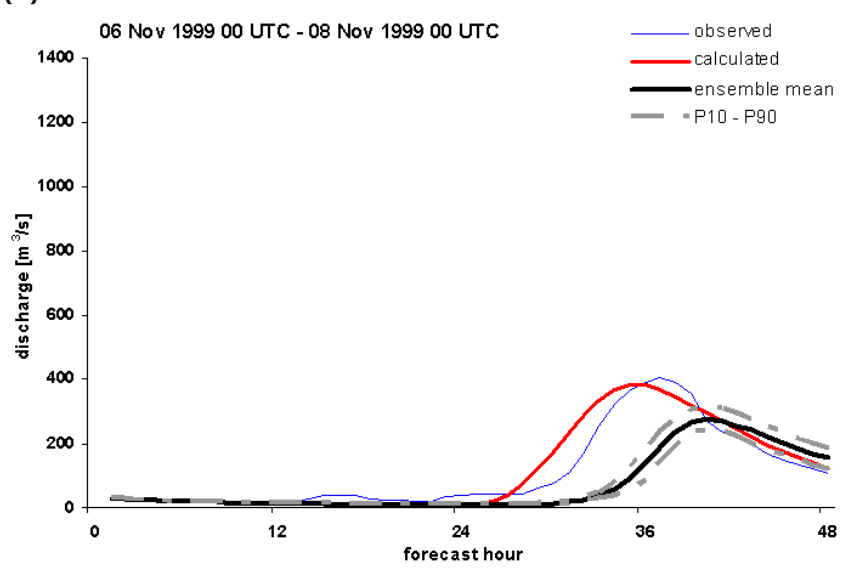

(c)

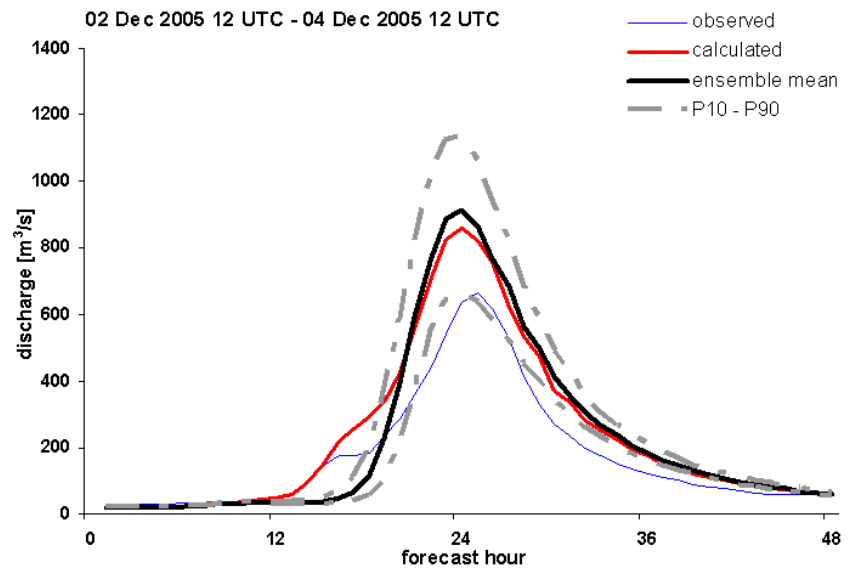

(b)

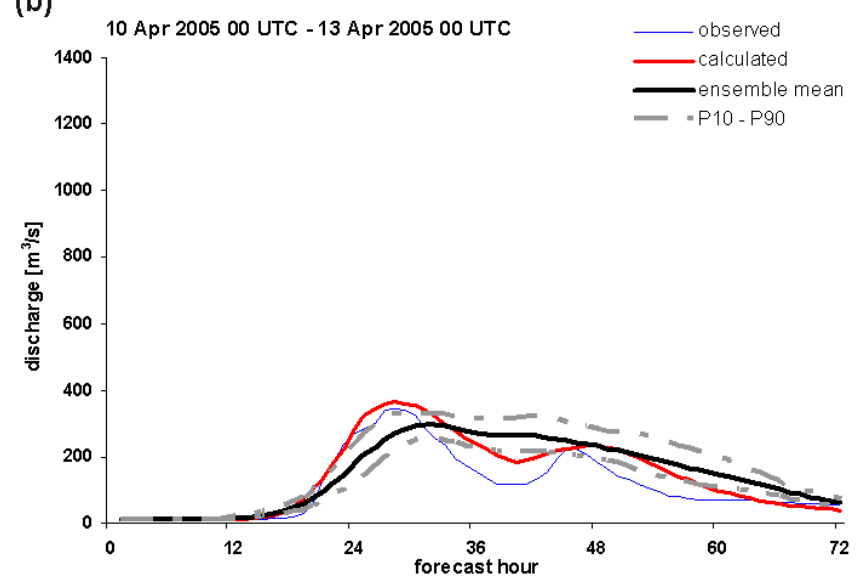

(d)

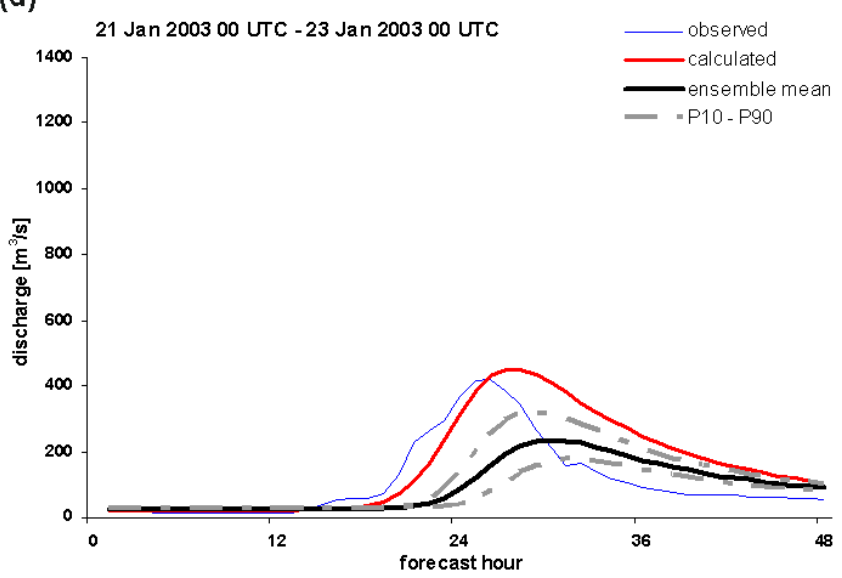

(e)

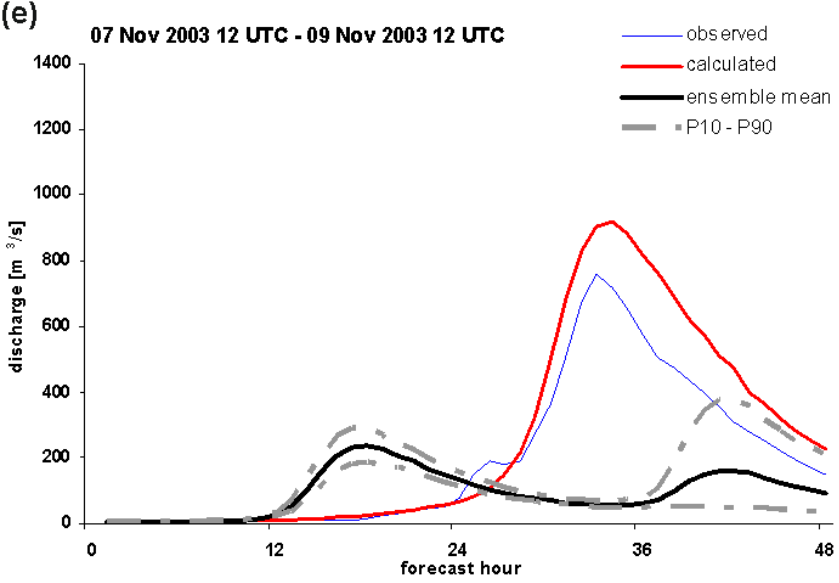

Fig. 12. Ensemble discharge forecasts $\left(\mathrm{m}^{3} / \mathrm{s}\right)$ vs. forecast time (h) for: (a) 6-7 Nov 1999 event; (b) 10-12 April 2005 event; (c) 2-3 Dec 2005 event; (d) 21-23 Jan 2003 event; (e) 7-9 Nov 2003 event. The bold line represents the ensemble mean, while the two grey dashed lines represent the P10 and P90 curves (see text). Red line is the discharge computed with raingauge observation, blue line is the observed discharge. 
to the considered forecast range, while the magnitude of the events can be appropriately estimated by the decision makers considering the ensemble results from a probabilistic point of view. Therefore, the proposed coupled system seems to be promising for operational use in the prediction of flood events and for timely warning purposes.

The hydrological response of the Reno river basin, as simulated by the TOPKAPI model, turns out to be quite sensitive not only to the total precipitation amount, but also to its correct space-time localization. This aspect supports the usefulness of an ensemble approach which takes into account the uncertainty associated to QPF. However, the multi-model ensemble allows to represent only that fraction of the total uncertainty, in the forecasting process, associated with the model error. This limitation could be overcome both increasing the number of ensemble members (models) or perturbing the initial and boundary conditions (Tibaldi et al., 2006). The latter procedure would generate a multi-model, multi-analysis ensemble displaying a larger variability since it takes into account also the evolution of the error associated to the initial condition. This larger ensemble should improve the performance of the meteo-hydrological forecasting system, especially for episodes like that of 7-9 November 2003, in which the main source of error seems ascribable to the global model analysis/forecast, driving the high resolution models. This will be the subject of future investigations.

Finally, it is worth noting that the obtained results might be also affected by the filtering operated by the hydrological model, whose structure affects the performances of the integrated real-time flood forecasting system implemented for the Reno river basin. Generally, the hydrological model performance appears not to be fully satisfactory, being the calculated curve higher and wider than the observed one. This overestimation can be probably ascribed to three different factors: an inaccurate reproduction of the infiltration processes in the hydrological model, leading to an overestimation of precipitation available for runoff; the method employed to spatially distribute the observed precipitation (i.e. the Thiessen Polygon method) that can cause an overestimation of the total amount of rainfall over regions scarcely covered with raingauges; the presence of a small hydroelectric reservoir, located in the upper Reno river basin, not modelled within the TOPKAPI framework, whose impact may not be negligible (Ranzi et al., 2007). For these reasons, we are planning to test different hydrological models over the Reno river basin as well as to implement the proposed multi-model approach over different catchments.

Acknowledgements. This work has been partly supported by the project RISK AWARE, INTERREG IIIB, CADSES, by the Italian National Civil Protection in the framework of the MOD-MET Project and by the project PROSCENIO coordinated by CIMA.

Edited by: L. Ferraris

Reviewed by: M.-C. Llasat and another anonymous referee

\section{References}

Bacchi, B. and Ranzi, R.: Runoff and Atmospheric Processes for Flood Hazard Forecasting and Control, Contract ENV4-CT970552, Final report, Brescia, Italy, 2000.

Buzzi, A. and Tibaldi, S.: Cyclogenesis in the lee of the Alps: a case study, Q. J. Roy. Meteor. Soc., 104, 271-287, 1978.

de Roo, A. P. J., Gouweleeuw, B., Thielen, J., Bartholmes, J., Bongioannini-Cerlini, P., Todini, E., Bates, P., Horritt, M., Hunter, N., Beven, K. J., Pappenberger, F., Heise, F., Rivin, G., Hills, M., Hollingsworth, A., Holst, B., Kwadijk, J., Reggiani, P., van Dijk, M., Sattler, K., and Sprokkereef, E.: Development of a European Flood Forecasting System, Int. J. River Basin Management, 1, 49-59, 2003.

Davolio, S. and Buzzi, A.: A nudging scheme for the assimilation of precipitation data into a mesoscale model, Weather Forecast., 19, 855-871, 2004.

Davolio, S., Buzzi, A., and Malguzzi, P.: High resolution simulations of an intense convective precipitation event, Meteorol. Atmos. Phys., 95, 139-154, 2007.

Diomede, T., Davolio, S., Marsigli, C., Miglietta, M. M., Moscatello, A., Papetti, P., Paccagnella, T., Buzzi, A., and Malguzzi, P.: Discharge prediction based on multi-model precipitation forecasts, Meteorol. Atmos. Phys., in press, 2008.

Ebert, C., Bàrdossy, A., and Bliefernicht, J.: Integration strategy for ensemble predictions of a limited area model into a short-range flood forecasting system, Proceedings of the CHR-Workshop Expert Consultation "Ensemble prediction and uncertainties in flood forecasting", Bern, Switzerland, 107-108, 2006.

Gebhardt, C., Theis, S., Krahe, P., and Renner, V.: Experimental ensemble forecasts of precipitation based on a convection-resolving model, 3rd HEPEX workshop, Book of Abstracts, European Commission EUR22861EN, edited by: Thielen., J., Bartholmes, J., and Schaake, J., 54-57, 2007.

Gouweleeuw, B., Thielen, J., de Roo, A. P. J., and Buizza, R.: Flood forecasting using probabilistic weather predictions, Hydrol. Earth Syst. Sci., 9, 87-102, 2005, http://www.hydrol-earth-syst-sci.net/9/87/2005/.

Hamill, T., Clark, M., Schaake, J., and Buizza, R.: Second HEPEX Workshop Summary Report, Boulder, Colorado, http://hydis8. eng.uci.edu/hepex/scndwksp/HEPEX05-Summary.pdf, 2005.

Hou, D., Mitchell, K., Toth, Z., Lohmann, D., and Wei, H.: Ensemble streamflow forecasting with the coupled GFS-NOAH modeling system, 3rd HEPEX workshop, Book of Abstracts, European Commission EUR22861EN, edited by: Thielen, J., Bartholmes, J., and Schaake, J., 65-68, 2007.

Kain, J. S.: The Kain-Fritsch convective parameterization: an update, J. Appl. Meteorol., 43, 170-181, 2004.

Klemp, J. B., Skamarock, W. C., and Dudhia, J.: Conservative splitexplicit time integration methods for the compressible nonhydrostatic equations, Mon. Weather Rev., 135, 2897-2913, 2007.

Koussis, A. D., Lagouvardos, K., Mazi, K., Kotroni, V., Sitzmann, D., Lang, J. G., Zaiss, H., Buzzi, A., and Malguzzi, P.: Flood forecasts for urban basin with integrated hydro-meteorological model, J. Hydrol. Eng., 8, 1-11, 2003.

Krzysztofowicz, R.: Bayesian theory of probabilistic forecasting via deterministic hydrologic model, Water Resour. Res., 35(9), 2739-2750, 1999.

Krzysztofowicz, R.: The case for probabilistic forecasting in hydrology, J. Hydrol., 249, 2-9, 2001. 
Liu, Z. and Todini, E.: Towards a comprehensive physically-based rainfall-runoff model, Hydrol. Earth Syst. Sci., 6, 859-881, 2002, http://www.hydrol-earth-syst-sci.net/6/859/2002/.

Marsigli, C., Boccanera, F., Montani, A.., and Paccagnella, T.: The COSMO-LEPS mesoscale ensemble system: validation of the methodology and verification, Nonlin. Processes Geophys., 12, 527-536, 2005, http://www.nonlin-processes-geophys.net/12/527/2005/.

Melone, F., Barbetta, S., Diomede, T., Perucacci, S., Rossi, M., Tessarollo, A., and Verdecchia, M.: Review and selection of hydrological models - Integration of hydrological models and meteorological inputs, Resulting from Work Package 1, Action 13, RISK AWARE - INTERREG III B - CADSES, 34 pp., http://www.smr.arpa.emr.it/riskaware/get.php?file= Report_WP1.13.pdf, 2005.

Michalakes, J., Dudhia, J., Gill, D., Henderson, T., Klemp, J., Skamarock, W., and Wang, W.: The Weather Research and Forecast Model: Software Architecture and Performance, Proceedings of the 11th ECMWF Workshop on the Use of High Performance Computing In Meteorology, Reading, U.K., Ed. George Mozdzynski, http://www.wrf-model.org/wrfadmin/docs/ ecmwf_2004.pdf, 2004.

Montani, A., Marsigli, C., Nerozzi, F., and Paccagnella, T.: Soverato flood in Southern Italy: performance of global and limitedarea ensemble forecasts, Nonlin. Processes Geophys., 10, 261274, 2003, http://www.nonlin-processes-geophys.net/10/261/2003/.

Moore, R. J., Cole, S. J., Bell, V. A., and Jones, D. A.: Issues in flood forecasting: ungauged basins, extreme floods and uncertainty, IAHS Publ. 305, Frontiers in Flood Research, Kovacs Colloquium UNESCO, Paris, June/July 2006, 103-122, 2006.

Pappenberger, F., Beven, K. J., Hunter, P. D., Bates, B. T., Gouweleeuw, J., Thielen, J., and de Roo, A. P. J.: Cascading model uncertainty from medium range weather forecasts (10 days) through a rainfall-runoff model to flood inundation predictions within the European Flood Forecasting System (EFFS), Hydrol. Earth Syst. Sci., 9, 381-393, 2005, http://www.hydrol-earth-syst-sci.net/9/381/2005/.

Ramos, M. H., Thielen, J., and Bartholmes, J.: EFAS EPS-based forecasts: in-depth case study and statistical evaluation of summer 2005 and spring 2006 flood forecasts, 3rd HEPEX workshop, Book of Abstracts, European Commission EUR22861EN, edited by: Thielen., J., Bartholmes, J., and Schaake, J., 97-100, 2007.
Ranzi, R., Zappa, M., and Bacchi, B.: Hydrological aspects of the Mesoscale Alpine Programme: findings from field experiments and simulations, Q. J. Roy. Meteor. Soc., 133, 867-880, 2007.

Richard, E., Buzzi, A., and Zängl, G.: Quantitative precipitation forecasting in the Alps: the advances achieved by the Mesoscale Alpine Programme, Q. J. Roy. Meteor. Soc., 133, 831-846, 2007.

Rossa, A.: COST 731 - Propagation of uncertainty in advanced meteo-hydrological forecast systems, http://cost731. bafg.de/servlet/is/Entry.9691.Display, 2005.

Rotach, M., Bouttier, F., Buzzi, A., Dorninger, M., Frustaci, G., Mylne, K., Ranzi, R., Richard, E., Schär, C., Staudinger, M., Volkert, H., and Wulfmeyer, V.: MAP D-PHASE, A Forecast Demonstration Project in the framework of MAP, http://www.map.meteoswiss.ch/map-doc/dphase/dphase documents.htm, 2005.

Schaake, J. C., Hamill, T. M., Buizza, R., and Clark, M.: HEPEX, the Hydrological Ensemble Prediction Experiment, B. Am. Meteorol. Soc., 88, 1541-1547, 2007.

Siccardi, F., Boni, G., Ferraris, L., and Rudari, R.: A Hydrometeorological approach for probabilistic flood forecast, J. Geophys. Res., 110, D05101, doi:10.1029/2004JD005314, 2005.

Skamarock, W. C., Klemp, J. B., Dudhia, J., Gill, D. O., Barker, D. M., Wang, W., and Powers, J. G.: A description of the Advanced Research WRF Version 2, NCAR Technical Note, NCAR/TN468+STR, 88, 100 pp., 2005.

Thielen, J., Bartholmes, J., Ramos, M. H., Kalas, M., and de Roo, A. P. J.: The European flood alert system: early flood warning based on ensemble prediction system products, 3rd HEPEX workshop, Book of Abstracts, European Commission EUR22861EN, edited by: Thielen., J., Bartholmes, J., and Schaake, J., 111-115, 2007.

Tibaldi, S., Paccagnella, T., Marsigli, C., Montani, A., and Nerozzi, F.: Limited-area ensemble forecasting: the COSMO-LEPS system. In Predictability of weather and climate, Cambridge University Press, 489-513, 2006.

Tiedtke, M.: A comprehensive mass flux scheme for cumulus parameterization in large-scale models, Mon. Weather Rev., 117, 1779-1799, 1989.

Todini, E. and Ciarapica, L.: The TOPKAPI model, in: Mathematical models of large watershed hydrology, edited by: Singh, V. P., Frevert, D. K., Littleton, Colorado, USA, Water Resources Publications, 914 pp., 2002. 